Atmos. Chem. Phys. Discuss., doi:10.5194/acp-2016-553, 2016

\title{
Numerical Analysis of the Role of Snowpack in the Ozone Depletion Events during the Arctic Spring
}

\author{
Le Cao ${ }^{1}$, Ulrich Platt ${ }^{2}$, Chenggang Wang ${ }^{1}$, Nianwen $\mathrm{Cao}^{1}$, and Qing Qin ${ }^{1,3}$ \\ ${ }^{1}$ Key Laboratory for Aerosol-Cloud-Precipitation of China Meteorological Administration, Nanjing University of Information \\ Science and Technology, Nanjing, China \\ ${ }^{2}$ Institute of Environmental Physics, University of Heidelberg, Heidelberg, Germany \\ ${ }^{3}$ Meteorological Bureau of Yushan, Yushan, China \\ Correspondence to: L. Cao \\ (le.cao@nuist.edu.cn)
}

\begin{abstract}
The tropospheric ozone depletion events (ODEs) and the related enhancement of reactive bromine in the boundary layer were observed in the springtime of Arctic almost 40 years ago. It is found that various substrates in polar regions such as the snowpack are able to release bromine, which is responsible for the consumption of ozone in the boundary layer. In the present simulation, a snowpack module which represents the mass transfer between the ambient air and the snowpack is implemented in a box model, aiming to clarify the influences of the snowpack on ODEs and the associated bromine explosion in the ambient air as well as in the interstitial air of the snowpack. In the snowpack module, the processes including the deposition of bromine containing compounds onto the snowpack, the mass exchange between the snow interstitial air and snow particles, and the release of $\mathrm{Br}_{2}$ from the snowpack to the ambient air are parameterized by estimating the transfer resistances which an air parcel experiences when being transported through the boundary layer into the snowpack.
\end{abstract}

The present model successfully captures the complete removal of ozone both in the boundary layer and in the snow interstitial air. The temporal and spatial distributions of bromine species such as $\mathrm{Br}_{2}$ are shown and compared with observations. By changing the properties of the snowpack, it is found that the size of snow grains, volume fraction of the liquid-like layer (LLL), and the rate of the mass exchange between the snow interstitial air and the snow particles are the critical parameters which determine the occurrence of ODEs. The simulation results show that a smaller size of the snow grains considerably accelerates the ozone depletion process. Moreover, the decrease of LLL volume fraction in snow grains is found to slow down the scavenging process of $\mathrm{HOBr}$ by the snow particles, which prohibits the occurrence of ODEs in the snowpack. In addition, according to the simulations with the modification of the snowpack thickness, the depletion of ozone in the ambient air is shown to be influenced more heavily by the bromine explosion occurring in the surface snow layers instead of the deep snow layers.

The importance of each step in the mass transfer processes occurring between the boundary layer and the snowpack is identified by conducting a local concentration sensitivity analysis. It is shown that the snow chemistry occurring in the surface snow layers has a relatively larger impact on the depletion of ozone in the ambient air compared to that within the deep snow layers. Besides, during the period of the ozone depletion, the mixing ratio of ozone in the boundary layer is mostly influenced by the deposition of $\mathrm{HOBr}$ onto the surface snow layers and the release of $\mathrm{Br}_{2}$ from the snow layers close to the ground surface. 
Atmos. Chem. Phys. Discuss., doi:10.5194/acp-2016-553, 2016

Atmospheric

Chemistry

Published: 7 July 2016

(c) Author(s) 2016. CC-BY 3.0 License.

and Physics

Discussions

(c) (i)

In contrast to that, in the interstitial air of the surface snow layer, the uptake of HOBr by snow particles is indicated as the most dominant step for the ODE.

\section{Introduction}

Ozone $\left(\mathrm{O}_{3}\right)$ is an important trace gas which was first discovered in Dr. Schoebein's experiment on the water electrolysis

5 (Schoenbein, 1840). Due to its unique role in the atmosphere, ozone has attracted great and broad attentions. It acts as the precursor of many oxidants in the atmosphere, and heavily controls the oxidation ability of the atmosphere. Moreover, ozone is able to absorb most of the ultraviolet radiations from the sun as well as the long-wave radiation from the ground surface, which alters the radiation budget on the earth. Thus, the study of ozone is always the focus of the scientific community.

In different layers of the lower atmosphere, two different ozone depletion episodes occur. In the stratosphere, the most wellknown ozone depletion phenomenon, "ozone hole", is annually observed in the spring of Antarctic. The occurrence of this phenomenon is attributable to the existence of the polar stratospheric clouds (PSCs), polar vortex, occurrence of the photolysis reactions as well as the heterogeneous reactions in the stratosphere. In contrast, in the troposphere, a different type of ozone depletion events (ODEs) occurs in the springtime of polar regions. These tropospheric ODEs were first observed by Oltmans (1981) by using two different types of ozone detectors in the year 1978 at Barrow, Alaska. It is found that within a couple of days, the surface ozone mixing ratio declines from the background level to less than $1 \mathrm{ppb}$ or even under the instrument detection limit, and these tropospheric low-ozone episodes last for several days. Later, in the year 1985, Bottenheim et al. observed a similar ozone depletion event at Alert, Canada, which confirms the finding of Oltmans (1981). Moreover, in a following field study during April 1986, Barrie et al. found an elevation of the mixing ratios of bromine species during ODEs. Since then, a number of ODEs and related enhanced bromine concentrations in the troposphere have been reported from various sites of Arctic (Helmig et al., 2007c, 2012; Halfacre et al., 2013) and also from several observation stations in Antarctic (Kreher et al., 1997; Frieß et al., 2004; Jones et al., 2006; Wagner et al., 2007; Jones et al., 2009, 2010).

The tropospheric ODEs occurring in the springtime of Arctic have a great influence on the human beings and the climate on the earth (Simpson et al., 2007). During ODEs, the oxidation ability of the atmosphere is dominated by the enhanced bromine oxidants instead of ozone. Thus, the final products of chemical reactions in the troposphere and the lifetime of many atmospheric components are altered. For instance, compared with the ozone-rich environment in Arctic, the gas-phase mercury (Hg) in Arctic during ODEs becomes more easily oxidized by the reactive bromine species. As a result, more reactive gaseous mercury (RGM) are formed and then land on the snow and ice surface through deposition processes. When the temperature increases in the late spring or summertime, the deposited RGM are carried by the water from the melting ice and snow, and flow into the ocean. Through the oceanic circulation, the extra $\mathrm{Hg}$ would finally enter the body of human beings at mid-latitudes, damaging their health. Aside from this impact on the oxidation ability of the atmosphere, another major influence of ODEs is that as ozone is a typical greenhouse gas which can absorb the long-wave radiation emitted from the earth and keep the surface warm, the decline of the ozone mixing ratio in the troposphere decreases the temperature of polar regions, which alters the 
Atmos. Chem. Phys. Discuss., doi:10.5194/acp-2016-553, 2016

Atmospheric

Chemistry

Published: 7 July 2016

(c) Author(s) 2016. CC-BY 3.0 License.

and Physics

Discussions

(c) (i)

melting speed of glacier and the climate in polar regions. This impact of ODEs on radiative forcing is more obvious in polar regions where the content of water vapor is poor in the atmosphere.

Since the observation performed by Barrie et al. (1988) showing the high bromine level during ODEs, the role of the halogen species in the depletion of ozone has been noticed. The temporal behavior of the halogen species especially bromine shows an anti-correlation with the ozone mixing ratio, which indicates the importance of bromine in the destruction of ozone. Previous studies (Hausmann and Platt, 1994; Platt and Hönninger, 2003; Simpson et al., 2007; Abbatt et al., 2012) have suggested that the bromine species are involved in an auto-catalytic reaction cycle, which converts ozone to oxygen molecules without any loss of bromine. Moreover, a "bromine explosion" mechanism which is able to explain the sharp increase of the bromine level in the troposphere is proposed. The gas phase hypobromous acid ( $\mathrm{HOBr}$ ) produced by the oxidation of BrO is absorbed by various polar substrates such as the suspended aerosols, and then reacts with bromide ions stored in these substrates, forming $\mathrm{Br}_{2}$. The $\mathrm{Br}_{2}$ molecules produced by the reactions between $\mathrm{HOBr}$ and bromide gather at the surface of the substrates and then evade into the ambient air, leading to the enhancement of bromine concentration in the air. In the presence of sunlight, Br molecules are photolyzed, forming Br atoms which are able to consume ozone. As a result, ODEs are accelerated. A thorough review of the bromine explosion mechanism for ODEs is provided by Platt and Hönninger (2003), Simpson et al. (2007) and Abbatt et al. (2012).

A number of numerical models have been developed to improve the understanding of the ODE-related physical and chemical processes. The existing models can be categorized as follows:

1. Box models. The box models, or called 0-D models, are the first models used to study ODEs. In the early 1980s, by using box models, a lot of efforts were paid to investigate the heterogeneous recycling processes at various substrate surfaces and identify the sources of bromine during ODEs (Fan and Jacob, 1992; Tang and McConnell, 1996; Michalowski et al., 2000; Evans et al., 2003). The potential bromine sources proposed in these studies include: ice surface, snowpack, sea salt aerosols, frost flowers and blowing snow. Since the year 2000, the triggering of ODEs has been studied by using box models (Sander et al., 2006; Morin et al., 2008; Sander and Morin, 2010). In the year 2014, Cao et al. (2014) use a box model KINAL to calculate the local concentration sensitivity of a reaction mechanism of ODEs, revealing a group of important reactions for the occurrence of ODEs.

2. One-dimensional models. According to the simulation results of a one-dimensional model, Lehrer et al. (2004) proposed the turbulent mixing intensity at the top of the atmospheric boundary layer as the key factor for the occurrence of ODEs by showing that a layer of low mixing intensity (i.e. a temperature inversion) is a prerequisite for the bromine explosion preceding ODEs. In the year 2008, Saiz-Lopez et al. (2008) developed a one-dimensional chemical transport model THAMO (Tropospheric HAlogen chemistry MOdel), showing the snowpack emission of $\mathrm{Br}_{2}$ to be important for maintaining the high level of bromine in the boundary layer during ODEs. Besides, it is also found by Saiz-Lopez et al. (2008) that the recycling of bromine on sea salt aerosols is essential for yielding a uniform BrO vertical distribution. Thomas et al. $(2011,2012)$ use a 1-D model MISTRA-SNOW with the implementation of a snow module, and they suggest that the heterogeneous recycling processes on the sea salt aerosols and the snowpack are essential for the occurrence of 
Atmos. Chem. Phys. Discuss., doi:10.5194/acp-2016-553, 2016

Manuscript under review for journal Atmos. Chem. Phys.

Chemistry

Published: 7 July 2016

(c) Author(s) 2016. CC-BY 3.0 License.

and Physics

Discussions

(c) (i)

ODEs. The importance of snowpack is also suggested by Toyota et al. (2014) by using a 1-D model PHANTAS. It is found by Toyota et al. that in the top layers of the snowpack, the release of $\mathrm{Br}_{2}$ is dominantly driven by the bromine explosion mechanism. In contrast, in deeper layers of snowpack, both the aqueous radical chemistry and the bromine explosion mechanism contribute to the bromine evasion to the boundary layer. Recently, a 1-D model, KINAL-T, has been developed by Cao et al. (2016), aiming to investigate the linkage between the height change of the atmospheric boundary layer and the occurrence and termination of ODEs.

3. Three-dimensional models. By adopting BrO data from satellite observations, Zeng et al. (2003, 2006) successfully reproduce ODEs by using a 3-D model. In the year 2008, a global 3-D model, GEM-AQ/Arctic, is used by Zhao et al. (2008), and their 3-D model includes a chemical reaction module and a long-range transport module. Zhao et al. (2008) suggest that the aerosols derived from the frost flowers might be a major source of bromine during ODEs. Yang et al. (2008, 2010) use a 3-D model to investigate the implications of bromine for the tropospheric ozone in polar regions, and they suggest that the blowing snow might be a source of bromine in the troposphere. Another version of GEM-AQ model with the incorporation of gas-phase and heterogeneous bromine chemistry is employed by Toyota et al. (2011) to explain the bromine sources for the BrO-clouds observed in Arctic boundary layer during ODEs (Chance, 1998; Richter et al., 1998; Platt and Wagner, 1998; Wagner et al., 2001). In their modeling results, oxidation of $\mathrm{Br}^{-}$by ozone at the snow/ice-covered surfaces is indicated as the primary source of the reactive bromine. Cao and Gutheil (2013) use a 3-D model with the incorporation of large eddy simulation to identify the influence of the turbulent mixing in the boundary layer on ODEs. In this publication, the impacts of the meteorological conditions such as the wind speed and the boundary layer stability on ODEs are discussed as well.

Despite these existing numerical studies on ODEs and the related bromine explosion mechanism, the source of the high-level bromine during ODEs still remains as a matter of debate. The suggested potential bromine sources include sea-salt aerosols, ice/snow-covered surfaces, frost flower fragments lifted by wind, blowing snow under strong wind conditions and organic emissions. Moreover, the suggested chemical mechanisms encompass the bromine explosion, oxidation of bromide by ozone, and $\mathrm{OH}$ reactions. Recently, the importance of snowpack for releasing bromine is identified. Snow, which covers most areas of polar regions, contains a large amount of bromide and chloride ions. Thus, adequate reactive bromine can be provided by the snowpack in Arctic for the ozone destruction. Moreover, due to its porous property and the enlarged surface area, snowpack may facilitate the heterogeneous recycling of the bromine species. As a result, the ozone consumption in the boundary layer might be favored due to the presence of the snowpack.

The significance of the snowpack during ODEs has also been suggested by several previous studies. In the multiphase box model CREAMS (Chemical Reactions Modeling System) used by Michalowski et al. (2000), the increased amount of bromine during ODEs is assumed to partly originate from a disordered water layer of the snowpack. It is found in their model that after switching off the entire snowpack interactions, the ozone depletion process is shut down, which indicates that the snowpack plays as the primary source of bromine. Saiz-Lopez et al. (2008) used the one-dimensional model THAMO to investigate the source strengths of bromine and iodine required for sustaining the vertical structure of BrO and IO observed at Halley 
Atmos. Chem. Phys. Discuss., doi:10.5194/acp-2016-553, 2016

Manuscript under review for journal Atmos. Chem. Phys.

Station during the CHABLIS field campaign. In their model, prescribed $\mathrm{Br}_{2}$ and atom I fluxes from the snowpack are included. It is found that the $\mathrm{Br}_{2}$ flux emitted from the snowpack is essential for keeping the model simulations in accordance with DOAS measurements in the field campaign. Thomas et al. $(2011,2012)$ coupled a snow module to the 1-D atmospheric model MISTRA, and the new physical-chemical system is referred to as MISTRA-SNOW. The uptake, recycling and release of bromine and reactive nitrogen oxides $\left(\mathrm{NO}_{\mathrm{x}}\right)$ in the interstitial air of snowpack are treated in great detail. After three-day model run, it is found by Thomas et al. that a significant bromide is still available in the liquid-like layer of the snowpack, which indicates that the snowpack is able to provide adequate reactive bromine to sustain the observed BrO level. However, neither in the boundary layer nor in the interstitial air of snowpack a strong destruction of ozone is observed in their model results. In a recent numerical study of Toyota et al. (2014), a 1-D physical-chemical model PHANTAS with a detailed treatment of the chemistry within the ambient and the snow interstitial air is developed to address the influence of snowpack on the ozone loss in the polar boundary layer. In their model, the snowpack acts as the sole bromine source and releases reactive bromine via the bromine explosion mechanism. The rapid ozone depletion as well as the enhanced bromine both in the boundary layer and within the interstitial air are successfully captured in the PHANTAS model.

Although the significance of the snowpack during ODEs has been investigated by the studies mentioned above, the uncertainties regarding the role of snowpack in ODEs remain large. The unanswered questions include:

\section{What is the influence on the ozone depletion rate caused by changes of the physical properties of the snowpack?}

The snowpack can be represented by the physical parameters such as the thickness of the snowpack, density, liquid-like layer (LLL) volume fraction, and snow grain radius. Our current understanding of the impacts caused by the changes of these snow properties on the ozone consumption is still poor. Take the snowpack thickness for instance, if the thickness increases, the surface area provided by the snowpack for the heterogeneous bromine recycling is enlarged, which may speed up ODEs in the boundary layer. However, as the diffusion in deeper layers becomes slower, the release of bromine from the snowpack increases less than proportional with the snowpack thickness. Therefore, it is difficult to estimate the impacts on the ozone depletion rate brought about by the change of the snowpack thickness during ODEs.

2. What is the relative importance of each step in the bromine explosion mechanism for the ozone destructions in the boundary layer and in the snow interstitial air?

As the sequence of the bromine explosion mechanism in snowpack consists of multiple steps including the deposition of gas-phase $\mathrm{HOBr}$ through the boundary layer, wind ventilation through the snowpack interstitial air, aqueous reactions occurring in the liquid-like layer of the snow grains, and the release of $\mathrm{Br}_{2}$ from the snowpack to the ambient air, it is of essential to know which step in this sequence is rate-determining as it critically controls the occurrence of the bromine explosion and the ozone depletion in the boundary layer as well as in the snow interstitial air. Moreover, as the dependence of the ozone mixing ratio on each step varies with time, it is also needed to clarify the steps which significantly influence the ozone depletion rate in the time periods before, during and after ODEs.

Therefore, in the present study, we aim to address the issues listed above. The organization of the manuscript is as follows. In Sect. 2, the model used in the present study and the relevant mathematical equations are described. Great attention is paid 
Atmos. Chem. Phys. Discuss., doi:10.5194/acp-2016-553, 2016

Manuscript under review for journal Atmos. Chem. Phys.

to the detailed treatment of the mass exchange between the boundary layer and the snowpack. Next, the computational results are presented in Sect. 3. At the beginning of Sect. 3, the temporal evolution of ozone and bromine species are shown. The time scales of the simulated ODEs and the mixing ratios of the chemical species such as $\mathrm{BrO}$ and $\mathrm{Br}_{2}$ during ODEs are compared with the results obtained in previous studies. Later on, different values of the snowpack properties such as the diameter of the snow grains are tested in order to investigate the influences caused by these changes on ODEs. At the end of Sect. 3, the relative importance of each step in the sequence of the bromine explosion mechanism on the depletion of ozone is indicated by performing a local concentration sensitivity analysis. At the end of the manuscript, Sect. 4 gives a summary of the major conclusions obtained in the present study. Possible improvements of the present model for future studies are also discussed.

\section{Mathematical Model and Methods}

In order to investigate the mass exchange among the snowpack, snow interstitial air and the ambient air in the overlying boundary layer, a new box model KINAL-SNOW (KInetic aNALysis of reaction mechanics with SNOW chemistry) were developed by adding a snowpack module to the previous box model (Cao et al., 2014) based on the open-source software KINAL (Turanyi, 1990). In KINAL-SNOW, the temporal change of the species concentrations in a complex chemical reaction mechanism can be expressed as a function of the species concentrations $\boldsymbol{c}$ and the rate constants $\boldsymbol{k}$ of the chemical reactions,

$15 \frac{\mathrm{d} \boldsymbol{c}}{\mathrm{d} t}=\boldsymbol{f}(\boldsymbol{c}, \boldsymbol{k})+\boldsymbol{E}$.

In Eq. (1), $c$ is a column vector of the species concentrations, and $c_{i}$ represents the concentration of the $i$-th species. $t$ is the time. $k$ denotes a column vector of the reaction rate constants, and the $j$-th component, $k_{j}$, represents the rate coefficient of the $j$-th reaction. $\boldsymbol{E}$ denotes the source term of local emissions. In KINAL-SNOW, the solution of Eq. (1) is obtained by using a fourth-order semi-implicit Runge-Kutta scheme (Gottwald and Wanner, 1981).

For the purpose of considering the conversion from the relatively stable bromine containing compounds (e.g. $\mathrm{HOBr}$ ) to $\mathrm{Br}_{2}$, which occurs at the surfaces of the snow grains, we implemented a snowpack module which is described below.

\subsection{The Representation of Snowpack in the Model}

A snowpack with a depth of $35 \mathrm{~cm}$ (Toyota et al., 2014) is adopted in the model KINAL-SNOW and is divided into 7 uniform layers so that each snow layer has a thickness of $5 \mathrm{~cm}$. According to the measurements conducted during the Polar Sunrise Experiment (PSE) in the year 1994 and 1998, a typical snowpack density of $0.31 \mathrm{~g} \mathrm{~cm}^{-3}$ (Michalowski et al., 2000; Toyota et al., 2014) is used in the present model. Thus, in each layer of the snowpack with the volume $V_{\mathrm{E}}=5 \mathrm{~cm}^{3}$ and $1 \mathrm{~cm}^{2} \mathrm{cross}^{-}$ sectional area, the volume of the liquid content $V_{\mathrm{L}}=1.68 \mathrm{~cm}^{3}$ is obtained if the density of ice is approximately assumed as $0.92 \mathrm{~g} \mathrm{~cm}^{-3}$ (Toyota et al., 2014). The interstitial air thus occupies the volume of $V_{\mathrm{I}}=3.32 \mathrm{~cm}^{3}$ so that the porosity $\phi=$ $V_{\mathrm{I}} / V_{\mathrm{E}}=0.66$ is obtained. In the present model, the snow particles are assumed to be spherical and have the diameter $D$ of $1 \mathrm{~mm}$ (Michalowski et al., 2000; Thomas et al., 2011). Thus, the total surface area provided by the snowpack with the thickness $h_{\mathrm{t}}=35 \mathrm{~cm}$ can be estimated as $A_{\mathrm{L}}=V_{\mathrm{L}} \times h_{\mathrm{t}} /(D / 6)=7.08 \times 10^{-2} \mathrm{~m}^{2}$, and within each snow layer, the surface 
Atmos. Chem. Phys. Discuss., doi:10.5194/acp-2016-553, 2016

Manuscript under review for journal Atmos. Chem. Phys.

area $A_{\mathrm{L}, i}=A_{\mathrm{L}} / 7=1.01 \times 10^{-2} \mathrm{~m}^{2}$ is estimated. With respect to the whole computational domain with the boundary layer height of $L$, the surface area density $A_{\mathrm{eff}, i}$ of each snow layer in the simulation is calculated as $A_{\mathrm{eff}, i}=A_{\mathrm{L}, i} /\left(L \times 1 \mathrm{~cm}^{2}\right)$, and the value of $A_{\mathrm{eff}, i}=0.505 \mathrm{~m}^{-1}$ is obtained for a typical polar boundary layer height $L=200 \mathrm{~m}$ which is used in the present model.

Figure 1 shows the major steps of the mass exchange between the boundary layer air and the snowpack. We take the gasphase $\mathrm{HOBr}$ in the boundary layer as an example, the complete exchange process can be divided into five steps:

\section{The transfer of the chemical species from the boundary layer to the snowpack interstitial air}

At the beginning of this process, the gas-phase bromine containing compounds such as $\mathrm{HOBr}$ are carried from the boundary layer to the surface of the snowpack through the turbulent mixing and the molecular diffusion. Afterward, as a result of the wind pumping and the molecular diffusion, the $\mathrm{HOBr}$ molecules enter the snowpack and land on different layers of the snowpack. To simulate this process, it is needed to consider the aerodynamic resistance $r_{a}$, quasi-laminar resistance $r_{b}$ due to the molecular diffusion, and $r_{s}$ which represents the vertical resistance that an air parcel undergoes when across different layers of the snowpack.

\section{The scavenging process of the bromine species in the snow interstitial air by the snow grains}

The HOBr molecules residing in the interstitial air frequently collide with the snow particles and are absorbed into the liquid-like layer of the snow grains. The formed liquid-phase $\mathrm{HOBr}$ are then involved in a bunch of aqueous reactions and facilitate the formation of $\mathrm{Br}_{2}$. The related aqueous reactions are discussed below. According to the previous study (Michalowski et al., 2000), it is assumed in the present model that this exchange process is similar to the mass exchange between the boundary layer air and the suspended aerosols, which depends on the radius of the snow particles, molecular diffusivity, and the value of the uptake coefficient of $\mathrm{HOBr}$ on the surfaces of the snow grains.

\section{The aqueous reactions converting bromide to $\mathrm{Br}_{2}$ in the liquid-like layer of the snow particles}

After the absorption of the gas-phase $\mathrm{HOBr}$ by the snow grains, the liquid-phase $\mathrm{HOBr}$ is formed and involved in the liquid reaction sequence as follows,

$\mathrm{HOBr}+\mathrm{H}^{+}+\mathrm{Br}^{-} \underset{k_{2}}{\stackrel{k_{1}}{\rightleftharpoons}} \mathrm{Br}_{2}+\mathrm{H}_{2} \mathrm{O}$

$\mathrm{HOBr}+\mathrm{H}^{+}+\mathrm{Cl}^{-} \underset{k_{4}}{\stackrel{k_{3}}{\rightleftharpoons}} \mathrm{BrCl}+\mathrm{H}_{2} \mathrm{O}$

$\mathrm{BrCl}+\mathrm{Br}^{-} \underset{k_{6}}{\stackrel{k_{5}}{\rightleftharpoons}} \mathrm{Br}_{2} \mathrm{Cl}$ 
Atmos. Chem. Phys. Discuss., doi:10.5194/acp-2016-553, 2016

Manuscript under review for journal Atmos. Chem. Phys.

Reaction (R1) consumes $\mathrm{H}^{+}$and bromide ions stored in the snow, forming $\mathrm{Br}_{2}$ which is then released to the interstitial air. However, the chloride storage in the snow is much larger than bromide. It is suggested that the $\mathrm{Cl}^{-} / \mathrm{Br}^{-}$ratio in the seawater reaches as high as 650:1 (Finlayson-Pitts and Pitts, 2000; Foster et al., 2001). When the seawater is deposited on the icepack through the snow falls, $\mathrm{Cl}^{-}$and $\mathrm{Br}^{-}$ions concentrate, leading to the decrease of the $\mathrm{Cl}^{-} / \mathrm{Br}^{-}$ratio to 188:1. The typical $\mathrm{Cl}^{-} / \mathrm{Br}^{-}$ratio in the snowpack measured in polar regions such as Alert ranges from 50 to 650 (Foster et al., 2001; Toom-Sauntry and Barrie, 2002). As a result, the majority of the aqueous HOBr molecules participate in the reaction sequence of (R3)-(R8), in which both $\mathrm{BrCl}$ and $\mathrm{Br}_{2}$ are formed. However, due to the decreased solubility of $\mathrm{Br}_{2}$ compared to $\mathrm{BrCl}$, the release of $\mathrm{Br}_{2}$ from the snow particles is favored.

These aqueous reactions are assumed to occur within the liquid-like layer (LLL) of the snowpack. LLL is a thin film covering the ice surface which consists of disordered water molecules. It is first discovered by Faraday (1859) from the experiments made at the temperature below the melting point of ice. The thickness of the LLL increases in the presence of the impurities, and the dissolved constituents concentrate in the LLL. Considering the current poor knowledge about the LLL on snow grains, we use a constant volume fraction of LLL which is taken from Michalowski et al. (2000), 0.2\% in the snowpack. Aside from this, a uniform distribution of the soluble in the LLL is also assumed.

\section{The release of $\mathrm{Br}_{2}$ from the snow particles to the interstitial air}

After the formation of gas-phase $\mathrm{Br}_{2}$ molecules at the surfaces of the snow grains, $\mathrm{Br}_{2}$ are then emitted to the interstitial air of the snowpack. This process is similar to step 2 mentioned above. However, different chemical species have different values of the mean molecular speed, uptake coefficient and Henry's constant. Thus, the exchange rate between the snow grains and the interstitial air should be estimated separately for each chemical species considered in the model.

\section{The emission of $\mathrm{Br}_{2}$ from the snowpack interstitial air to the boundary layer}

The gas-phase $\mathrm{Br}_{2}$ molecules in the snow interstitial air are then released to the boundary layer via the turbulent mixing and the molecular diffusion. The outgassing of $\mathrm{Br}_{2}$ to the boundary layer leads to the enhancement of the total amount of bromine in the boundary layer and also the acceleration of ODEs in the presence of sunlight. In our model, the parameterization of this emission process is as similar as that used for step 1. This treatment is also adopted in the previous numerical study conducted by Michalowski et al. (2000).

In the following context, the details of the parameterizations of these five steps for the snowpack module are discussed.

\subsubsection{Step 1}

In the present model, for simplicity, we only consider the deposition of $\mathrm{HOBr}$ and $\mathrm{BrONO}_{2}$ on the snowpack. The transfer of air parcels containing $\mathrm{HOBr}$ and $\mathrm{BrONO}_{2}$ from the boundary layer to the interstitial air can be expressed as 
Atmos. Chem. Phys. Discuss., doi:10.5194/acp-2016-553, 2016

Manuscript under review for journal Atmos. Chem. Phys.

Published: 7 July 2016

(c) Author(s) 2016. CC-BY 3.0 License.

(c) (i)
Atmospheric

Chemistry

and Physics

Discussions

$\mathrm{BrONO}_{2(\mathrm{BL})} \stackrel{k_{10}}{\longrightarrow} \mathrm{BrONO}_{2(\mathrm{SIA}, \mathrm{i})}$.

In reactions (R9) and (R10), the subscript "BL" denotes the boundary layer air, while "SIA, $i$ " represents the snowpack interstitial air in the $i$-th layer. The estimation of the reaction rate constant $k_{9}$ depends on the parameterization of the aerodynamic resistance $r_{a}$, quasi-laminar resistance $r_{b}$, and the vertical resistance $r_{s}$ across each layer within the snowpack.

The aerodynamic resistance, $r_{a}$, in the boundary layer can be estimated by using Eq. (2) with neglecting the molecular diffusion in the boundary layer,

$r_{a}=\int_{z_{0}}^{z_{s}}\left(\kappa u_{*} z\right)^{-1} \mathrm{~d} z=\frac{1}{\kappa u_{*}} \ln \left(\frac{z_{s}}{z_{0}}\right)$.

In Eq. (2), $z_{s}$ is the height of the surface layer which is approximately $10 \%$ of the boundary layer height (Stull, 1988). In the present model, a boundary layer height $L=200 \mathrm{~m}$ is assumed since the typical thickness of the boundary layer in polar regions ranges from $100 \mathrm{~m}$ to $500 \mathrm{~m}$ (Stull, 1988). Therefore, $z_{s}$ has the value of $20 \mathrm{~m}$ in the present study. $z_{0}=10^{-4} \mathrm{~m}$ is the roughness length of the snowpack surface (Stull, 1988). The variation of the roughness length due to the mobility of the snowpack under high-wind conditions (Andreas et al., 2004) has not been included in the model yet. $\kappa=0.41$ is the von Karman's constant, and $u_{*}$ is the friction velocity which is estimated as

15

$u_{*}=(\kappa W) / \ln \left(\frac{z_{s}}{z_{0}}\right)$.

In Eq. (3), $W$ is the reference wind speed at the height $z_{s}$, and a typical wind speed $W=8 \mathrm{~m} \mathrm{~s}^{-1}$ in Arctic is used (Beare et al., 2006; Cao et al., 2014). Thus, for $\mathrm{HOBr}$ and $\mathrm{BrONO}_{2}$, the aerodynamic resistance across the boundary layer is

$r_{a}=\frac{1}{\kappa^{2} W}\left(\ln \left(\frac{z_{s}}{z_{0}}\right)\right)^{2}=111 \mathrm{sm}^{-1}$.

After being carried through the boundary layer, $\mathrm{HOBr}$ and $\mathrm{BrONO}_{2}$ molecules experience the resistance $r_{b}$ due to molecular diffusion in the interfacial layer. In this layer, the molecular diffusion dominates instead of the turbulent diffusion. According to Huff and Abbatt $(2000,2002)$, the quasi-laminar resistance $r_{b}$ can be estimated as

$r_{b}=\frac{z_{0}}{D_{\mathrm{g}}}$

in which $D_{\mathrm{g}}$ is the molecular diffusivity and is assumed to have a constant value $0.2 \mathrm{~cm}^{2} \mathrm{~s}^{-1}$ (Lehrer et al., 2004) for each chemical species. As a result, $r_{b}$ is calculated as $r_{b}=z_{0} / D_{\mathrm{g}}=\left(10^{-4} \mathrm{~m}\right) /\left(0.2 \times 10^{-4} \mathrm{~m}^{2} \mathrm{~s}^{-1}\right)=5 \mathrm{sm}^{-1}$ for both $\mathrm{HOBr}$ and $\mathrm{BrONO}_{2}$.

When a strong wind blows over the snowpack with irregular geometries, a pressure variation along the streamline above the snowpack is formed. The pressure gradient within the snowpack also leads to a ventilation of the air through the layers of the snowpack, which is called "wind pumping". Thus, the vertical movement of the trace air parcel through the snow layers depends on not only the molecular diffusion but also the diffusion due to wind pumping. To account for the wind ventilation in 
Atmos. Chem. Phys. Discuss., doi:10.5194/acp-2016-553, 2016

Manuscript under review for journal Atmos. Chem. Phys.

the snow interstitial air, an additional diffusivity $D_{\mathrm{pump}, i}$ is added to the overall effective diffusivity $D_{\mathrm{eff}, i}$ within the snowpack (Thomas et al., 2011; Toyota et al., 2014),

$D_{\text {eff }, i}=\frac{D_{\mathrm{g}}}{\tau_{g}}+D_{\text {pump }, i}$.

The first term in the right hand side of Eq. (6) represents the effective molecular diffusivity (Thomas et al., 2011; Toyota et al.,

5 2014). $\tau_{g}$ is the tortuosity of the snowpack and has a value of 2 for polar snowpack (Albert and Shultz, 2002). The estimation of $D_{\text {pump }, i}$ is taken following the work of Thomas et al. (2011). It is calculated using the expression as

$D_{\text {pump }, i}=U_{\text {firn }, i} \Delta z$,

in which $\Delta z$ is the thickness of each snowpack layer in the model. In our present model, $5 \mathrm{~cm}$ is used. $U_{\mathrm{firn}, i}$ in Eq. (7) denotes the vertical wind pumping speed which can be written as Eq. (8) according to Cunningham and Waddington (1993),

$10 \quad U_{\text {firn }, i}=\frac{6 k \rho_{\text {air }}}{\pi \mu \lambda_{\text {surf }}} \frac{h}{\lambda_{\text {surf }}} \frac{\sqrt{\alpha^{2}+1}}{\alpha} W^{2} \exp \left(-\frac{z_{i}}{\delta}\right)$,

where $\delta$ is defined as

$\delta=\frac{1}{2} \frac{\alpha}{\sqrt{\alpha^{2}+1}} \frac{\lambda_{\text {surf }}}{\pi}$.

In Eq. (8), $k$ is the permeability, $\rho_{\text {air }}$ is the air density and a constant value $1.29 \mathrm{~kg} \mathrm{~m}^{-3}$ is given. $\mu$ is the dynamic viscosity of air, and $\lambda_{\text {surf }}$ is the relief wavelength. $h$ is the relief amplitude. $\alpha$ is the aspect ratio of the relief between the horizontal and vertical directions. The values of these parameters are taken from Thomas et al. (2011) and listed in the supplementary material. $W=8 \mathrm{~m} \mathrm{~s}^{-1}$ is the reference wind speed at the height of $20 \mathrm{~m} . z_{i}$ is the depth of the central point of the $i$-th snowpack layer from the ground surface. It can be seen from Eq. (8) that the wind pumping rate decreases with depth, representing that the snow in deeper layers is less accessible. The vertical resistance of the $i$-th snowpack layer is then computed as

$r_{s, i}= \begin{cases}z_{i} / D_{\mathrm{eff}, i}, & \text { if } i=1, \\ r_{s, i-1}+\left(z_{i}-z_{i-1}\right) / D_{\mathrm{eff}, i}, & \text { if } 1<i \leq 7 .\end{cases}$

20 With respect to the seven snow layers considered in the model, the vertical resistances $r_{s,(i=1, \ldots, 7)}$ have the values of 1597 , $6597,11597,16597,21597,26597$ and $31597 \mathrm{~s} \mathrm{~m}^{-1}$, respectively.

The deposition velocity $v_{\mathrm{d}, i}$ of gas-phase $\mathrm{HOBr}$ and $\mathrm{BrONO}_{2}$ on the $i$-th layer of the snowpack is thus calculated as

$v_{\mathrm{d}, i}=\left(r_{a}+r_{b}+r_{s, i}\right)^{-1}$.

The rate constants of reactions (R9) and (R10), $k_{9}$ and $k_{10}$, for the $i$-th layer are thus calculated as

$k_{9, i}=k_{10, i}=v_{\mathrm{d}, i} A_{\mathrm{eff}, i}$

in which $A_{\mathrm{eff}, i}=0.505 \mathrm{~m}^{-1}$ is the surface area density of each snow layer which has been discussed above. The values of the reaction rate constants $k_{9,(i=1, \ldots, 7)}$ for the seven layers in the present model are $2.95 \times 10^{-4} \mathrm{~s}^{-1}, 7.53 \times 10^{-5} \mathrm{~s}^{-1}$, $4.32 \times 10^{-5} \mathrm{~s}^{-1}, 3.02 \times 10^{-5} \mathrm{~s}^{-1}, 2.33 \times 10^{-5} \mathrm{~s}^{-1}, 1.89 \times 10^{-5} \mathrm{~s}^{-1}$ and $1.59 \times 10^{-5} \mathrm{~s}^{-1}$. The rate constants for reaction (R10), $k_{10,(i=1, \ldots, 7)}$, have the same values. 
Atmos. Chem. Phys. Discuss., doi:10.5194/acp-2016-553, 2016

Manuscript under review for journal Atmos. Chem. Phys.

\subsubsection{Step 2}

After arriving at each layer within the snowpack, the gas-phase $\mathrm{HOBr}$ is absorbed by the snow particles. This scavenging process can be written as

$\operatorname{HOBr}_{(\text {SIA }, \mathrm{i})} \stackrel{k_{11}}{\underset{k_{12}}{\longrightarrow}} \mathrm{HOBr}_{(\text {liquid,i) }}$

5 In reactions (R11) and (R12), the gas-phase $\mathrm{HOBr}$ and the liquid-phase $\mathrm{HOBr}$ in the $i$-th layer are converted to each other. In contrast to that, the absorption of the gas-phase $\mathrm{BrONO}_{2}$ by the snow grains is not included in the present model yet. Instead, $\mathrm{BrONO}_{2}$ in the snow interstitial air is assumed to be involved in a heterogeneous reaction (R13),

$\mathrm{BrONO}_{2(\mathrm{SIA}, \mathrm{i})}+\mathrm{H}_{2} \mathrm{O} \stackrel{k_{13}}{\longrightarrow} \mathrm{HOBr}_{(\text {liquid }, \mathrm{i})}+\mathrm{H}^{+}+\mathrm{NO}_{3}^{-}$.

In reaction (R13), the hydrolysis of $\mathrm{BrONO}_{2}$ contributes to the formation of liquid-phase $\mathrm{HOBr}$ and $\mathrm{H}^{+}$ions in the liquid-like layers of the snow grains. As these two resultants participate in the bromine explosion mechanism, it can be expected that reaction (R13) would consequently speed up the bromide activation from the snowpack.

The question remaining is that how to accurately estimate the rate constants of reactions (R11), (R12) and (R13) in the model. For reaction (R11), our parameterization is similar to the method used by Schwartz (1986) for the mass transfer between the boundary layer air and the suspended aerosols. The transfer rate, $k_{11, i}$, in each snowpack layer is represented as

$k_{11, i}=\left(\frac{r}{D_{\mathrm{g}}}+\frac{4}{v_{\text {therm }} \gamma}\right)^{-1} \frac{A_{\mathrm{LLL}, i}}{V}$.

In Eq. (13), $r=0.5 \mathrm{~mm}$ is the radius of the snow grains. $D_{\mathrm{g}}=0.2 \mathrm{~cm}^{2} \mathrm{~s}^{-1}$ is the gas-phase molecular diffusivity. $v_{\text {therm }}$ is the molecular mean speed, and is given by $v_{\text {therm }}=\sqrt{(8 \mathrm{R} T) /\left(\pi M_{\mathrm{HOBr}}\right)}=237.13 \mathrm{~m} \mathrm{~s}^{-1}$ for HOBr. $\gamma$ is the uptake coefficient of $\mathrm{HOBr}$ on snow grains. A constant value $\gamma=0.06$ is used for $\mathrm{HOBr}$ (Sander and Crutzen, 1996). The term $A_{\mathrm{LLL}, i} / V$ is the surface area density of the liquid-like layer in the $i$-th snow layer of the computational domain. In previous model studies, a constant volume fraction of the LLL is normally used (Michalowski et al., 2000; Liao and Tan, 2008; Thomas et al., 2011) Thus, in the present model, we adopted a constant value $0.2 \%$ from the multi-phase box model constructed by Michalowski et al. (2000). As a result, the term $A_{\mathrm{LLL}, i} / V$ can be written as $\left(0.002 \times A_{\mathrm{L}, i}\right) / V$. At present, the increase of the snow density with depth is not considered in the model. Thus, $A_{\mathrm{L}, i}$ is assumed as a constant and has the value of $1.01 \times 10^{-2} \mathrm{~m}^{2}$ as discussed above. Because all the units of the species concentrations in our model are converted to molecules $/\left(1 \mathrm{~cm}^{3}\right.$ boundary layer air), in Eq. (13), $V=$ (boundary layer height $200 \mathrm{~m}) \times\left(\right.$ cross-sectional area $\left.1 \mathrm{~cm}^{2}\right)$ is used instead of the total volume of the snowpack. The rate constant for reaction (R11) $k_{11, i}=4.0 \times 10^{-5} \mathrm{~s}^{-1}$ is thus obtained for each snowpack layer.

With respect to the reverse reaction (R12), according to Michalowski et al. (2000), the rate constant of reaction (R12) is equal to the rate constant of the forward reaction divided by the dimensionless Henry's law constant $H R T$ and the total volume fraction of the LLL in the computational domain,

$30 \quad k_{12, i}=\frac{k_{11, i}}{H R T} /\left(\frac{V_{\mathrm{LLL}}}{V}\right)$. 
Atmos. Chem. Phys. Discuss., doi:10.5194/acp-2016-553, 2016

Manuscript under review for journal Atmos. Chem. Phys.

In Eq. (14), $H$ is the Henry's law constant of $\mathrm{HOBr}$ which has the value of $4.8 \times 10^{1} \mathrm{~mol}(\mathrm{~L} \mathrm{~atm})^{-1}$ (Sander and Crutzen, 1996; Michalowski et al., 2000). $R=0.082(\mathrm{~L} \mathrm{~atm})(\mathrm{mol} \mathrm{K})^{-1}$ is the universal gas constant. $T$ is the temperature, and a constant value $258 \mathrm{~K}$ is used in the model. $V_{\mathrm{LLL}} / V$ is the total volume fraction of the LLL, and it is estimated as $V_{\mathrm{LLL}} / V=$ $\left(0.2 \% \times V_{\mathrm{L}, \text { tot }}\right) / V=1.18 \times 10^{-6}$, in which $V_{\mathrm{L}, \text { tot }}$ denotes the total liquid volume in the snowpack. As a result, the reaction 5 rate constant $k_{12, i}$ can be computed as $3.34 \times 10^{-2} \mathrm{~s}^{-1}$.

Similarly, the parameterization of the heterogeneous reaction (R13) can be conducted using the same expression as Eq. (13) to derive the first-order reaction rate constant $k_{13, i}$. As the molecular mean speed of $\mathrm{BrONO}_{2}$ is estimated as $196.13 \mathrm{~m} \mathrm{~s}^{-1}$ at the temperature $258 \mathrm{~K}$, the value of $k_{13, i}=3.99 \times 10^{-5} \mathrm{~s}^{-1}$ is obtained.

\subsubsection{Step 3}

Currently, four groups of the liquid reactions, (R1)-(R8), is included in the KINAL-SNOW model. The aqueous reaction rate constants are listed in Tab. 1. As mentioned above, the unit of the species concentrations used in the present model is in the form of molecules/ $\left(1 \mathrm{~cm}^{3}\right.$ boundary layer air). Thus, the original liquid reaction rate constants should be divided by $\left(V_{\mathrm{LLL}} / V\right)^{n-1}$, in which $n$ is the reaction order. The prescribed species concentrations in the snowpack are listed in Tab. 2 which represent the average concentrations in the wintertime bulk snow samples (Toom-Sauntry and Barrie, 2002). A PH value of 4 is initialized for the melted surface snow. It is assumed in the model that the bromide and chloride storage observed in the melted surface snow are all concentrated in the LLL. Therefore, the exact initial concentrations of $\mathrm{Br}^{-}, \mathrm{Cl}^{-}$and $\mathrm{H}^{+}$used in the model are divided by the volume fraction of the LLL in the snowpack, $0.2 \%$, which gives the initial concentrations of $\mathrm{Br}^{-}, \mathrm{Cl}^{-}$and $\mathrm{H}^{+}$in the liquid-like layer the values of $1.00 \times 10^{-4} \mathrm{~mol} \mathrm{~L}^{-1}, 4.50 \times 10^{-3} \mathrm{~mol} \mathrm{~L}^{-1}$ and $5.00 \times 10^{-2} \mathrm{~mol} \mathrm{~L}^{-1}$, respectively.

\subsubsection{Step 4}

$\mathrm{The}_{2}$ molecules formed in the liquid reaction sequence (R1)-(R8) are rapidly emitted to the interstitial air through a similar exchange pathway as described in step 2. The transfer of $\mathrm{Br}_{2}$ between the interstitial air and the snowpack particles can be written in the form of

$\mathrm{Br}_{2(\text { SIA }, \mathrm{i})} \underset{k_{15}}{\stackrel{k_{14}}{\longrightarrow}} \mathrm{Br}_{2 \text { (liquid,i) }}$

Similar to step 2, the rate constants of reactions (R14) and (R15) are parameterized using Eqs. (13) and (14). The molecular mean speed of $\mathrm{Br}_{2}$ is calculated as $184.77 \mathrm{~m} \mathrm{~s}^{-1}$ with the temperature $258 \mathrm{~K}$. According to Sander and Crutzen (1996) and Michalowski et al. (2000), The uptake coefficient $\gamma=0.01$ is used for $\mathrm{Br}_{2}$ in the present model. The reaction rate constants are then calculated as $k_{14, i}=3.72 \times 10^{-5} \mathrm{~s}^{-1}$ and $k_{15, i}=1.19 \times 10^{-1} \mathrm{~s}^{-1}$ for every snow layer.

\subsubsection{Step 5}

The last step of this sequence is the release of $\mathrm{Br}_{2}$ molecules from the interstitial air to the ambient air in the boundary layer, 
Atmos. Chem. Phys. Discuss., doi:10.5194/acp-2016-553, 2016

Manuscript under review for journal Atmos. Chem. Phys.

As this process is also dominated by the combined effect of the turbulent mixing in the boundary layer, molecular diffusion through the interfacial layer and the influence of wind pumping within the snowpack, we adopted the same values of the transfer coefficients used in step 1. This assumption has also been justified by Michalowski et al. (2000). The rate constants of reaction (R16) for each layer are $2.95 \times 10^{-4} \mathrm{~s}^{-1}, 7.53 \times 10^{-5} \mathrm{~s}^{-1}, 4.32 \times 10^{-5} \mathrm{~s}^{-1}, 3.02 \times 10^{-5} \mathrm{~s}^{-1}, 2.33 \times 10^{-5} \mathrm{~s}^{-1}$, $51.89 \times 10^{-5} \mathrm{~s}^{-1}$ and $1.59 \times 10^{-5} \mathrm{~s}^{-1}$.

\subsection{The Representation of Suspended Aerosols in the Model}

The importance of the aerosols for ODEs is identified for releasing bromine and providing surfaces for the recycling of the halogen species, although it is found in previous studies that the suspended aerosols alone are unable to sustain the high-level bromine (Impey et al., 1997, 1999; Michalowski et al., 2000; Lehrer et al., 2004; Cao et al., 2014). Generally speaking, the treatments of the suspended aerosols in previous model studies can be divided into two categories. The first type is that the aerosols in the model are assumed initially halogen-free. The aerosols play the role of absorbing gas-phase $\mathrm{HOBr}$ and $\mathrm{HBr}$, and providing the place for the heterogeneous bromine recycling. The other type of the aerosol treatment implemented in previous models is preformed by assuming that the aerosols in the model play as a direct source of the bromine emission. As the focus of our present study is on the mass exchange between the boundary layer air and the snowpack, the former type of the parameterization which is more convenient to be implemented in the box model is adopted (Lehrer et al., 2004; Cao and Gutheil, 2013; Cao et al., 2014). It is assumed that there is no initial bromide or chloride storage in the suspended aerosols in the boundary layer. As a result, the release speed of $\mathrm{Br}_{2}$ by the aerosols is limited by the uptake of both $\mathrm{HOBr}$ and $\mathrm{HBr}$ in the boundary layer, which can be written as the form of

$\mathrm{HOBr}_{(\mathrm{g})}+\mathrm{HBr}_{(\mathrm{g})} \stackrel{k_{17}}{\longrightarrow} \mathrm{Br}_{2(\mathrm{~g})}+\mathrm{H}_{2} \mathrm{O}$.

20 The second-order exchange rate constant $k_{17}$ can be expressed as

$k_{17}=\left(\frac{r}{D_{\mathrm{g}}}+\frac{4}{v_{\text {therm }} \gamma}\right)^{-1} \alpha_{\text {eff }}$,

where $r$ is the average radius of the suspended aerosols. $D_{\mathrm{g}}$ in Eq. (15) denotes the gas-phase molecular diffusivity, and $v_{\text {therm }}$ is the mean molecular speed of $\mathrm{HOBr} . \gamma$ represents the uptake coefficient of $\mathrm{HOBr}$ on aerosols, and the estimation of $\gamma$ depends on the absorption rate of both gaseous $\mathrm{HOBr}$ and $\mathrm{HBr}$ by the suspended aerosols and the rate of the aqueous reaction between $\mathrm{HOBr}$ and $\mathrm{HBr}$ (Hanson et al., 1994). $\alpha_{\text {eff }}$ is the surface area density of the suspended aerosols, which represents the total area provided by the aerosols divided by the total volume of the computational domain. The details of this parameterization can be found in Lehrer et al. (2004) and Cao et al. (2014). It is estimated that for a gas-phase HBr mixing ratio of $10 \mathrm{ppt}$, the rate constant of reaction (R17) is $6.14 \times 10^{-4} \mathrm{~s}^{-1}$ when $\mathrm{HOBr}$ is abundant.

\subsection{The Calculation of the Photolysis Frequencies}

30 For the photolysis reactions occurring in the boundary layer, the first-order reaction rates used in Lehrer et al. (2004) are taken (see Tab. 3). These values are calculated by using a three-stream radiation transfer model (Röth, 1992, 2002). The diurnal 
Atmos. Chem. Phys. Discuss., doi:10.5194/acp-2016-553, 2016

Atmospheric

Chemistry

Published: 7 July 2016

(c) Author(s) 2016. CC-BY 3.0 License.

and Physics

Discussions

(c) $\underset{\mathrm{By}}{\mathrm{i}}$

variation of the reaction rate has not been included in the present model yet. We have performed a sensitivity analysis to evaluate the influence on the ozone depletion rate brought about by the inclusion of the dark reactions and the change of SZA (Solar Zenith Angle), and only a slight difference is found for the depletion rate of ozone and the peak values of the bromine species during the time periods simulated. Moreover, earlier studies (Lehrer et al., 2004; Cao et al., 2014) have also proved that

5 the change of SZA has little effect on the temporal behavior of ozone and halogen species.

Within the snowpack, less sunlight is available in deeper layers. Therefore, the dependence of the photolysis frequencies on the depth should be taken into account. According to Thomas et al. (2011) and Toyota et al. (2014), the photolysis frequencies at different depth $z_{i}$ are calculated as

$J\left(z_{i}\right)=J_{0} \exp \left(-z_{i} / \epsilon_{\lambda}\right)$

10 In Eq. (16), $J\left(z_{i}\right)$ is the photolysis frequency in the snowpack at the depth $z_{i} . J_{0}$ is the photolysis frequency at the surface of the snowpack, which is assumed equal to the one in the ambient air. $\epsilon_{\lambda}$ is defined as the e-folding depth (King and Simpson, 2001), and the value $\epsilon_{\lambda}=7.5 \mathrm{~cm}$ (Toyota et al., 2014) is adopted. Thus, the photolysis frequency in the interstitial air of each snow layer is derived by multiplying the photolysis frequency at the snowpack surface by the factor $0.717,0.368,0.189,0.097$, $0.050,0.026$ and 0.013 for the seven snow layers, respectively.

\subsection{Model Initialization and Simulation Scenarios}

The initial mixing ratios of the gas-phase species in the boundary layer and the interstitial air are listed in Tab. 4. It is assumed that at the beginning of the simulation, the air in the boundary layer and the snow interstitial air contain $0.3 \mathrm{ppt} \mathrm{Br}_{2}$ and $0.01 \mathrm{ppt}$ $\mathrm{HBr}$, which can be provided by the photo-dissociation of bromoform $\left(\mathrm{CHBr}_{3}\right)$ (Tang and McConnell, 1996). All other trace gases not listed here have an initial concentration of zero.

The reaction steps representing the mass exchange between the boundary layer air and the snowpack are added to the original reaction mechanism taken from Lehrer et al. (2004) and Cao et al. (2014). Some new reactions are added and the reaction rate constants are also updated according to the latest version of the chemical kinetic data (Atkinson et al., 2006). A constant temperature of $258 \mathrm{~K}$ (Lehrer et al., 2004) is adopted for the estimation of the reaction rates. The updated reaction mechanism consists of 90 chemical reactions among 39 species, which is listed in the supplementary material. At present, bromine is considered as the only gas-phase halogen species in the model. Since in our model, seven snow layers as well as the atmospheric boundary layer are taken into account, the reaction mechanism taken from Lehrer et al. (2004) and Cao et al. (2014) should be applied to each layer of the model, leading to the total number of the reactions applied in the model amounting to 720 and the number of the chemical species to 312. After that, the mass exchange processes between the boundary layer air and the snowpack which have been described in Sect. 2.1 are added to the reaction mechanism as reactions (R721)-(R832) (see the supplement), and additional 49 aqueous-phase species within seven snow layers are also included.

In observations, several chemical species such as nitrogen oxides $\left(\mathrm{NO}_{\mathrm{X}}\right)$ and formaldehyde (HCHO) are found to be emitted from the snowpack in the presence of sunlight (Grannas et al., 2007). Thus, we employed the in-snow emissions of $\mathrm{NO}_{\mathrm{X}}$, $\mathrm{HONO}, \mathrm{H}_{2} \mathrm{O}_{2}$ and $\mathrm{HCHO}$ in the present model, and the values are taken from the earlier box model study (Cao et al., 2014) 
Atmos. Chem. Phys. Discuss., doi:10.5194/acp-2016-553, 2016

Manuscript under review for journal Atmos. Chem. Phys.

(see Tab. 5). The emission rates are estimated according to the data obtained in previous measurements (Jones et al., 2000, 2001; Jacobi et al., 2002), and the ratio of the emitted $\mathrm{HONO}$ and $\mathrm{NO}_{2}$ is set to 1.0 (Grannas et al., 2007). It is assumed that these chemical species are first released from the snow grains to the snow interstitial air, and then carried to the boundary layer due to the combined effect of the turbulent mixing and the molecular diffusion. The mass transfer of these chemical species released from the snowpack (e.g. $\mathrm{NO}_{\mathrm{x}}$ and $\left.\mathrm{HCHO}\right)$ to the boundary layer is implemented in the reaction mechanism as (R833)-(R902) in the present model.

We first run the simulation in the presence of a $35 \mathrm{~cm}$ snowpack with all the snowpack properties at their nominal values, which is refered to as "standard scenario". The temporal evolution of ozone and bromine containing compounds in the standard scenario are captured (Sect. 3.1). Then the properties of the snowpack such as the diameter of the snow grains and the volume fraction of LLL are altered. Thus, the influences on the ozone depletion and the bromine explosion caused by the changes of these snowpack properties are investigated (Sect. 3.2). The variations in the snowpack properties result in the following four categories of simulation scenarios which consist of 8 cases in total.

- Cases 1 \& 2: The diameter of the snow grains is changed from the original value $1 \mathrm{~mm}$ (Michalowski et al., 2000) to a value of $0.3 \mathrm{~mm}$ (Toyota et al., 2014) and $2 \mathrm{~mm}$ (Thomas et al., 2011). In order to perform this modification, the surface area provided by each $5 \mathrm{~cm}$ snow layer for the bromine activation, $A_{\mathrm{L}, i}$, is altered to $0.34 \times 10^{-1} \mathrm{~m}^{2}$ for $0.3 \mathrm{~mm}$ snow grains and $0.505 \times 10^{-2} \mathrm{~m}^{2}$ for $2 \mathrm{~mm}$ snow grains. As a result of this change, modifications of the deposition velocity of $\mathrm{HOBr}$ and $\mathrm{BrONO}_{2}$, exchange rate between the snow interstitial air and the snow particles, and the release speed of $\mathrm{Br}_{2}$ to the ambient air are also needed.

- Cases $3 \& 4$ : The volume fraction of the LLL in the snowpack is varied from $0.2 \%$ (Michalowski et al., 2000) to a value of $3.03 \times 10^{-5}$ which has been used in the MISTRA-SNOW model (Thomas et al., 2011) and a middle value $0.02 \%$. Due to the decline of the LLL volume in the model, the absorption rates of $\mathrm{HOBr}, \mathrm{BrONO}_{2}$ and $\mathrm{Br}_{2}$ by the snow grains are reduced. However, since the soluble in the model is assumed to concentrate in the LLL, the reduction of the LLL volume leads to the enhancement of the soluble concentration in the LLL and the consequent speedup of the aqueous reactions.

- Cases 5 \& 6: The initial PH value of the snow particles is modified from the original value of 4 to 7 and 10 , which represents that the type of the snowpack is changed from acidic to neutral and alkaline. This modification is made by multiplying the $\mathrm{H}^{+}$ion concentration in the snow grains by $10^{-3}$ and $10^{-6}$, leading to the $\mathrm{H}^{+}$concentrations of $1.0 \times 10^{-7} \mathrm{~mol} \mathrm{~L}^{-1}$ and $1.0 \times 10^{-10} \mathrm{~mol} \mathrm{~L}^{-1}$ in the melted snow.

- Cases 7 \& 8: The default thickness of the snowpack $(35 \mathrm{~cm})$ is increased to $50 \mathrm{~cm}$ or decreased to $5 \mathrm{~cm}$ by adding or removing several snow layers from the model. For the implementation of the $50 \mathrm{~cm}$ snowpack, three additional snow layers are added to the bottom of the snowpack. As a result of this modification, 138 species and 348 reactions representing the snow chemistry occurring within the additional three layers are added to the reaction mechanism. Thus, the complete reaction mechanism applied in this simulation scenario consists of 1250 reactions among 499 chemical species. Apart from this modification, the ratio between the total liquid volume of the snowpack and the volume of the computational 
Atmos. Chem. Phys. Discuss., doi:10.5194/acp-2016-553, 2016

Manuscript under review for journal Atmos. Chem. Phys.

domain is increased due to the enhancement of the snowpack thickness. The ratio increases from the original value $5.9 \times 10^{-4}$ (for seven snow layers) to $8.4 \times 10^{-4}$ (for 10 snow layers). The associated changes such as the reduction of the release speed of $\mathrm{Br}_{2}$ from the snow grains to the interstitial air are also made. In contrast to that, in the simulation with the presence of a $5 \mathrm{~cm}$ snowpack, only one snow layer is kept in the model. The volume ratio of the total liquid quantity in the computational domain is thus reduced to $8.4 \times 10^{-5}$, and the related modifications are also made in the model.

At last, a local concentration sensitivity analysis is performed on the reaction mechanism used in the present study (Sect. 3.3). In the concentration sensitivity analysis, the relative concentration sensitivity $S_{i j}$ is calculated as

$S_{i j}=\frac{\partial \ln c_{i}}{\partial \ln k_{j}}$.

In Eq. (17), $c_{i}$ is the concentration of the $i$-th species, and $k_{j}$ denotes the rate constant of the $j$-th reaction in the mechanism. The value of the concentration sensitivity $S_{i j}$ enables to identify the dependence of a specified chemical species on each step of the reaction mechanism used in the model (902 reactions among 361 chemical species). As a result, the relative importance of each sequence in the bromine explosion mechanism on the ozone mixing ratio either in the boundary layer or in the snow interstitial air can be exhibited by the relative concentration sensitivities. The solution of Eq. (17) is derived by using the subroutine SENS of the KINAL software based on the Decomposed Direct Method (Valko and Vajda, 1984).

\section{Results and Discussion}

In this section, the results of the simulations are presented and discussed.

\subsection{Temporal Behavior of Ozone and Bromine Species in the Boundary Layer and the Snowpack}

The time series of ozone and bromine containing compounds in the boundary layer and the snowpack for the standard scenario are shown in Figs. 2(a)-(d). In the boundary layer (i.e. regions above the height of $0 \mathrm{~m}$ ), ozone starts to decline after approximately day 2.3, decreasing rapidly from the background level of $40 \mathrm{ppb}$ to less than $1 \mathrm{ppb}$. The major ozone removal process takes approximately one day and a half, which is consistent with the typical time scale of ODEs observed by Oltmans (1981) and Bottenheim et al. (1986). In contrast to that, the onsets of the ozone depletion in the snowpack layers differ significantly. In the snow layers with the depth less than $10 \mathrm{~cm}$, ozone depletion starts after only 1.3 days which is earlier than the occurrence of the ODE in the boundary layer. As a result of this early ozone consumption in the snowpack close to the surface, ozone in the ambient air is more abundant than that in the interstitial air of the surface snow. Thus, the ozone mixing ratio shows a positive gradient between the snowpack and the ambient air. This finding is in accordance with the observations in which a positive gradient of ozone is usually found (Helmig et al., 2007a, b). Deeper in the snowpack, the snow grains and the interstitial air are less accessible, which causes the retardant of the ozone depletion in these layers. Thus, it is seen in Fig. 2(a) that in the layers deeper than $20 \mathrm{~cm}$, ozone is only partly consumed or stays at the background level ( $\sim 40 \mathrm{ppb})$. 
Atmos. Chem. Phys. Discuss., doi:10.5194/acp-2016-553, 2016

Atmospheric

Manuscript under review for journal Atmos. Chem. Phys.

Chemistry

Published: 7 July 2016

(c) Author(s) 2016. CC-BY 3.0 License.

and Physics

Discussions

(c) (i)

As the major formation pathway of $\mathrm{BrO}$ is $\mathrm{Br}+\mathrm{O}_{3} \rightarrow \mathrm{BrO}$, two factors are the prerequisites for the observation of $\mathrm{BrO}$ in the atmosphere: presence of ozone and drop of the ozone mixing ratio (Hausmann and Platt, 1994). Therefore, BrO is regarded as an important indicator of ODEs. In Fig. 2(b), the temporal and spatial distribution of BrO in the ambient air and the snowpack is displayed. The relatively rapid enhancement of $\mathrm{BrO}$ in the surface snow rather than in the deep layers is found, which is consistent with the ozone behavior discussed above. The peak values of $\mathrm{BrO}$ in the snow layers close to the surface and in the boundary layer are approximately $50 \mathrm{ppt}$. Moreover, the daily averaged $\mathrm{BrO}$ mixing ratios in the boundary layer on day 2,3 are 24.8 and $33.5 \mathrm{ppt}$, respectively. These values reside in a reasonable range reported in the BrO observations, i.e. $20-60 \mathrm{ppt}$ (Hausmann and Platt, 1994; Barrie et al., 1994; Kreher et al., 1997; Tuckermann et al., 1997; Hönninger and Platt, 2002; Frieß et al., 2004; Wagner et al., 2007; Liao et al., 2012).

The observation of in-snow bromine is difficult since the pumping of the interstitial air from the snowpack tends to mix the ambient air into the snowpack, thus influencing the accuracy of the data obtained. In March 2000, Foster et al. (2001) monitored several ODEs occurring at Alert, Canada and measured the mixing ratios of bromine precursors such as $\mathrm{Br}_{2}$ and $\mathrm{BrCl}$ by using atmospheric pressure CIMS (Chemical Ionization Mass Spectrometry). The highest mixing ratio of in-snow Br ${ }_{2}$, 2 ppt, is found by Foster et al. (2001), which is about twice the value measured in the ambient air (see the scattered points in Fig. 3). In contrast, in the 1-D physical-chemical model PHANTAS developed by Toyota et al. (2014) with a detailed treatment of the in-snow chemistry, $\mathrm{Br}_{2}$ reaches a maximum of $300 \mathrm{ppt}$ in the snowpack, about two orders of magnitude higher than the value reported by Foster et al. (2001). In the present study (see Fig. 2(c)), $\mathrm{Br}_{2}$ mixing ratio in the snow interstitial air ranges from 2 ppt to 10 ppt, which is similar to the value obtained by Foster et al. (2001). The vertical profile of the in-snow Br ${ }_{2}$ mixing ratio during the ODE (on day 3 ) in the present simulation is also displayed (see the dash dot line in Fig. 3). It is found that in the snow layers with the depth less than $10 \mathrm{~cm}$, the $\mathrm{Br}_{2}$ mixing ratio reaches a peak value of $4.6 \mathrm{ppt}$, which is approximately $1.3 \mathrm{ppt}$ higher than that in the ambient air $(\sim 3.3 \mathrm{ppt})$. Then the $\mathrm{Br}_{2}$ mixing ratio drops to a low value $(\sim 2.4 \mathrm{ppt})$ at the middle depth of the snowpack $(-15$ to $-20 \mathrm{~cm})$. In the deeper layers, the $\mathrm{Br}_{2}$ mixing ratio shows an increase again, reaching a value of $3 \mathrm{ppt}$ at the depth of $-30 \mathrm{~cm}$. The vertical profile of $\mathrm{Br}_{2}$ is similar to the measurements made by Foster et al. (2001). However, the value of $\mathrm{Br}_{2}$ mixing ratio in the model results is approximately $2.3 \mathrm{ppt}$ larger than that in the observations (see the curve line in Fig. 3). The discrepancy between the model results and the observations could be due to several reasons: It could be caused by the assumptions implemented in the model. The release of bromine from the LLL of the snow grains is assumed only in the form of $\mathrm{Br}_{2}$ while the release of $\mathrm{BrCl}$ is neglected. As a result of this assumption, a relatively higher $\mathrm{Br}_{2}$ concentration in the snow interstitial air is expectable in the model results. Moreover, during the sampling process of the observations, a forced mixing of the low $\mathrm{Br}_{2}$ air from the ambient air into the snowpack occurs, which may lead to a low $\mathrm{Br}_{2}$ mixing ratio in the interstitial air of the snowpack. In addition, the observation of $\mathrm{Br}_{2}$ by Foster et al. (2001) is made at an initial stage of the ODE, which implies that the actual $\mathrm{Br}_{2}$ concentration in the snow interstitial air during ODEs is probably higher than the value reported by Foster et al. (2001).

Figure 2(d) displays the vertical distribution of the total bromine amount with time. It is seen that due to the relatively rapid deposition rate of $\mathrm{HOBr}$ on the snow layers with the depth less than $10 \mathrm{~cm}$, a large quantity of bromide is released from these snow layers, leading to a strong enhancement of the total bromine amount in the surface snow. The peak values of the total 
Atmos. Chem. Phys. Discuss., doi:10.5194/acp-2016-553, 2016

Atmospheric

Chemistry

Manuscript under review for journal Atmos. Chem. Phys.

Published: 7 July 2016

(c) Author(s) 2016. CC-BY 3.0 License.

and Physics

Discussions

(c) $\underset{\mathrm{BY}}{\mathrm{B}}$

bromine amount in these shallow snow layers (depth lower than $10 \mathrm{~cm}$ ) are approximately $390 \mathrm{ppt}$, higher than those $(\sim 136 \mathrm{ppt})$ in the middle layers $(-15$ to $-25 \mathrm{~cm})$ of the snowpack. In the snow layers deeper than $25 \mathrm{~cm}$, the total bromine amount is found lower than $10 \mathrm{ppt}$, which is attributable to the slow exchange rate between these deep snow layers and the ambient air rich in $\mathrm{HOBr}$ so that the activation of bromide is unable to be accelerated.

Figure 4 displays the modeled mixing ratios of ozone and principal bromine containing compounds as a function of time within the $200 \mathrm{~m}$ boundary layer and in the snow interstitial air at the depth of $2.5 \mathrm{~cm}$. It can be seen in Fig. 4(a) that ozone depletion starts after day 2.3, before which little ozone is consumed. At the early time stage before day 2.3 , BrO and $\mathrm{HBr}$ mixing ratios show gradual growths and they constitute the major contributions to the total amount of bromine. Due to the presence of ozone, $\mathrm{Br}$ atoms are almost instantly converted to $\mathrm{BrO}$, and thus, they can be hardly observed at this time. After day 2.3 , as the $\mathrm{BrO}$ mixing ratio is continuously increasing, the formation of $\mathrm{HOBr}$ is favored, which leads to an enhancement of the $\mathrm{HOBr}$ mixing ratio in the ambient air. On about day $3, \mathrm{BrO}$ reaches a peak level of approximately 54 ppt. The maximum of $\mathrm{HOBr}, 7.5 \mathrm{ppt}$, is also found at this time. As the deposition of $\mathrm{HOBr}$ leads to an enhancement of the release of the reactive bromine from the snowpack which is able to consume ozone in the ambient air, a swift decrease of ozone is found during this time period. After day 5, when the ozone mole fraction falls down below $1 \mathrm{ppb}$, the formation pathway of BrO is unable to proceed, leading to the disappearance of $\mathrm{BrO}$. The mixing ratio of $\mathrm{Br}$ atom builds up to be a main constituent of the total bromine stock. The maximum value of Br mixing ratio in the ambient air is about $30 \mathrm{ppt}$. This amount of Br is then removed by the aldehydes (e.g. $\mathrm{HCHO}$ and $\mathrm{CH}_{3} \mathrm{CHO}$ ) in the air, forming $\mathrm{HBr}$. At the end of the depletion event, a high level of $\mathrm{HBr}$ resides in the air, which is in accordance with the aerosol measurements of Langendörfer et al. (1999).

It is of interest to note in Fig. 4(a) that the total bromine amount in the boundary layer undergoes a decline between day 3 and day 5 , and reaches a minimum value of about 34 ppt. Then the total bromine level rises again and keeps increasing until day 14 which is the end of the simulation. By analyzing the reaction mechanism applied in the present model, we found that the total bromine amount in the ambient air critically depends on the deposition rates of $\mathrm{HOBr}$ on the snowpack and the emission rates of $\mathrm{Br}_{2}$ from different snow layers. In the early stage of the ODE (before day 3), it is seen in Fig. 4(b) that the HOBr mixing ratio in the snowpack increases rapidly. Due to the relatively strong enhancement of $\mathrm{HOBr}$ in the snowpack, the formation of $\mathrm{Br}_{2}$ from the snow grains accelerates and consequently speeds up the outgassing of $\mathrm{Br}_{2}$ to the boundary layer. In contrast, the $\mathrm{HOBr}$ concentration in the ambient air is rather low (see Fig. 4(a)). Thus, in the boundary layer, the release speed of $\mathrm{Br}_{2}$ exceeds half of the deposition rate of $\mathrm{HOBr}$ in this time period. As a result, the bromine amount in the ambient air accumulates and reaches the peak value of approximately 84 ppt. However, after day 3, as the ozone in the surface snow is completely consumed (see Fig. 4(b)), the mixing ratio of $\mathrm{BrO}$ and $\mathrm{HOBr}$ in the snow interstitial air instantly drop to a level lower than 1 ppt. Consequently, the production of $\mathrm{Br}_{2}$ is strongly retarded and the release of $\mathrm{Br}_{2}$ to the boundary layer is also largely reduced. In contrast to that, the $\mathrm{HOBr}$ concentration in the boundary layer keeps stable as $\mathrm{BrO}$ is still abundant. Therefore, in this time period, the total bromine amount in the boundary layer decreases as the deposition of HOBr onto the snowpack is faster than twice of the release speed of $\mathrm{Br}_{2}$ from the snowpack. After day 5, as the $\mathrm{BrO}$ mixing ratio in the ambient air decreases until a near-zero value is achieved, the major formation pathway of $\mathrm{HOBr}$ is unable to proceed, which leads to a disappearance of $\mathrm{HOBr}$ in the ambient air. Meanwhile, the release speed of $\mathrm{Br}_{2}$ from the snowpack to the boundary layer remains stable. $\mathrm{These}$ released $\mathrm{Br}_{2}$ 
Atmos. Chem. Phys. Discuss., doi:10.5194/acp-2016-553, 2016

Atmospheric

Chemistry

Manuscript under review for journal Atmos. Chem. Phys.

Published: 7 July 2016

(c) Author(s) 2016. CC-BY 3.0 License.

and Physics

Discussions

(c) (i)

in this time period mostly originate from the deep snow layers where $\mathrm{BrO}$ and $\mathrm{HOBr}$ are still abundant. Therefore, the total bromine amount in the boundary layer starts to increase again. In contrast to that, in the interstitial air of the snowpack close to the ground (see Fig. 4(b)), after the complete removal of ozone, the release of $\mathrm{Br}_{2}$ and the deposition of $\mathrm{HOBr}$ from the boundary layer are negligible as the $\mathrm{Br}_{2}$ concentration in the interstitial air and the $\mathrm{HOBr}$ concentration in the ambient air are rather low, leading to a steady amount of the total bromine amount in the surface snow layer.

The temporal evolutions of ozone in the boundary layer and within the interstitial air of the snowpack are shown in Fig. 5 . As mentioned above, ozone in the boundary layer starts to decline significantly after day 2.3. The depletion rate exceeds $0.1 \mathrm{ppbh}^{-1}$, reaching the maximum of $2 \mathrm{ppbh}^{-1}$. In the snowpack, the onsets of ODEs depend on the depth. The occurrence of the ODE at the depth of $2.5 \mathrm{~cm}$ and $7.5 \mathrm{~cm}$ is earlier than that in the ambient air, starting on day 1.4 at the depth of $2.5 \mathrm{~cm}$ and on day 1.5 at the depth of $7.5 \mathrm{~cm}$. However, the duration of the ozone depletion in the ambient air and in the snow layers with the depth of $2.5 \mathrm{~cm}$ and $7.5 \mathrm{~cm}$ shows a similar time scale, lasting approximately 1.5 days. It is also seen in Fig. 5 that although the depletion of ozone at the depth of $7.5 \mathrm{~cm}$ occurs at a similar time as that in the boundary layer, approaching the end of the ODE (from day 3 to day 5), ozone in the boundary layer declines more gradually than that in the snowpack layer at $-7.5 \mathrm{~cm}$. The reason for this difference is due to the decline of the total bromine amount in the ambient air within this time period as discussed above. In the snow layers deeper than $7.5 \mathrm{~cm}$, ODEs occur later than that in the ambient air. In the layers at the depth of $27.5 \mathrm{~cm}$ and $32.5 \mathrm{~cm}$, the complete removal of ozone cannot be achieved within the 14 days simulated.

\subsection{Influence of Snowpack Properties on Ozone and Bromine Containing Compounds}

In this section, we vary the snowpack properties to investigate the mixing ratio change of ozone and bromine species.

\subsubsection{Snow Grain Diameter}

20 Figure 6(a) depicts the depletion of ozone occurring in each snowpack layer after changing the snow grain diameter to 0.3 mm (Toyota et al., 2014). Compared to the simulation with the original value of the snow grain diameter (see Fig. 5), in the present simulation, the onset of the ODE in the boundary layer is found two days earlier than in the standard scenario. Besides, the complete removal of ozone finishes earlier, on approximately half a day after day 1 . In the snow layers with the depth less than $12.5 \mathrm{~cm}$, ODEs are all accelerated due to the decrease of the snow grain diameter. We found that the acceleration of ODEs in the ambient air and the interstitial air of the surface snow layers is mostly attributable to the enhancement of the deposition rate of $\mathrm{HOBr}$, mass transfer between the snow interstitial air and the snow particles, and the release of $\mathrm{Br}_{2}$ when the size of the snow grains is reduced. In this situation, the deposition of $\mathrm{HOBr}$ and the absorption by the snow particles speed up in the shallow snow layers. Thus, the depletion of bromide in the snow grains is strengthened, which leads to a more rapid release of $\mathrm{Br}_{2}$ to the snow interstitial air and also an enhanced ozone depletion in these snow layers. $\mathrm{Meanwhile}$ the release of $\mathrm{Br}_{2}$ from the snowpack to the ambient air is also reinforced, which causes the acceleration of the ODE in the boundary layer.

It is interesting to note that the depletion of ozone in the boundary layer above this fine-size snowpack is earlier than that in the snow layers close to the ground, which means that a negative gradient of the ozone mixing ratio can be found under this condition. As mentioned above, in the observations, normally a positive ozone gradient is found. However, occasionally, 
Atmos. Chem. Phys. Discuss., doi:10.5194/acp-2016-553, 2016

Atmospheric

Chemistry

Published: 7 July 2016

(c) Author(s) 2016. CC-BY 3.0 License.

and Physics

Discussions

(c) (i)

negative ozone gradient events are reported when a rapid decline of ozone in the ambient air occurs (Galbally and Allison, 1972; Zeller and Hehn, 1996; Zeller, 2000). It is estimated by Helmig et al. (2007a) that the frequency of the occurrence of a negative ozone gradient event is approximately $12 \%$ of the number of cases when a positive ozone gradient is found. Helmig et al. (2007a) also report that during the events with a negative ozone gradient, the ozone mixing ratio in the snow interstitial

5 air is approximately $1-3$ ppb larger than that in the ambient air, which is also successfully captured in the present simulation. Thus, from the results of the present model, we suggest that a negative gradient of the ozone concentration near the surface can be found more frequently on a snowpack with a fine grain size.

In Fig. 6(a), it is also seen that in the snow layers deeper than $12.5 \mathrm{~cm}$, the influence brought about by the change of the grain size is opposite to that in the shallow snow layers. The ODEs in these deep layers are found to be decelerated. The reason for this difference is that the relative importance of each step in the present reaction mechanism for determining the depletion of ozone is different for the snow layers with different depth. In the shallow snow layers (depth $<12.5 \mathrm{~cm}$ ), the deposition rate of $\mathrm{HOBr}$ is relatively fast compared to the deep snow layers. As a result, the amount of $\mathrm{HOBr}$ for the acceleration of the bromine activation from the snow grains is adequate in these shallow layers, and thus the depletion of ozone depends more heavily on the mass exchange rate between the snow interstitial air and the snow grains. In contrast to that, in the deep snow layers (depth $\geq 12.5 \mathrm{~cm}$ ), as the deposition rate of $\mathrm{HOBr}$ is relatively small, the acceleration of the bromine explosion and the consequent ozone depletion are more critically controlled by the availability of the HOBr deposited from the ambient air. In the present simulation with a fine-size snowpack, ozone in the ambient air is rapidly consumed within 1.2 days, which causes the termination of the formation of $\mathrm{BrO}$ and $\mathrm{HOBr}$ in the boundary layer. Thus, the quantity of $\mathrm{HOBr}$ deposited on the deep layers is less than that under the condition of the original $1 \mathrm{~mm}$ snow grain diameter. Therefore, as HOBr is lacking in the deep layers for the bromine activation, even though the transfer rate between the snow interstitial air and the snow grains is increased due to the decrease of the snow particle size, the depletion of ozone is still delayed. We have also conducted a local concentration sensitivity analysis to investigate the dominant processes in the present reaction mechanism for the depletion of ozone in each snow layer, which is described in Sect. 3.3.

The diameter of the snow grains is then changed to $2 \mathrm{~mm}$. The relevant ozone temporal behavior is shown in Fig. 6(b). In comparison to the standard scenario (1 mm diameter snow grains) shown in Fig. 5, it is found that in the presence of the coarse snow grains, ODEs in the shallow snow layers as well as in the boundary layer are strongly retarded with an onset of the ozone depletion at the depth of $2.5 \mathrm{~cm}$ only after 6 days. In contrast, in the snow layers with the depth of $27.5 \mathrm{~cm}$ and $32.5 \mathrm{~cm}$, the increase of the snow grain size causes a slight acceleration of the ozone consumption. The possible mechanism responsible for this phenomenon is as similar as that mentioned above. The increase of the snow grain size causes the slow down of the ODE in the boundary layer so that HOBr can be continuously formed and then deposits on the deep snow layers. Consequently, the quantity of $\mathrm{HOBr}$ in the deep snow layers for the bromine explosion and the acceleration of the ODE is more abundant in this situation, which speeds up the depletion of ozone in these deep snow layers.

In summary, we can say that the size of the snow grains has a large influence on the induction time for an ODE event. 
Atmos. Chem. Phys. Discuss., doi:10.5194/acp-2016-553, 2016

Atmospheric

Chemistry

Published: 7 July 2016

(c) Author(s) 2016. CC-BY 3.0 License.

and Physics

Discussions

(c) (i)

\subsubsection{Liquid-Like Layer Volume Fraction}

In a second set of the numerical experiments, the volume fraction of the LLL is changed from the original value $0.2 \%$ (Michalowski et al., 2000) to $3.03 \times 10^{-5}$ (Thomas et al., 2011) and $0.02 \%$. It is found that after these modifications, neither in the boundary nor in any snow layer an ODE occurred within the 14 days simulated. Thus, we conclude that the LLL fraction in the snow grains is rather important for the occurrence of ODEs. As the modification of the LLL fraction in the snow grains leads to the change of the aqueous reaction rates and the transfer rates of $\mathrm{HOBr}$ and $\mathrm{Br}_{2}$ between the interstitial air and the snow particles, in order to clarify the reasons why the reduction of the LLL fraction leads to the nonoccurrence of ODEs, we have analyzed the relevant changes in the model brought about by the modification of the LLL fraction. We found that the major contribution to the ozone consumption by the reduction of the LLL fraction is the deceleration of the uptake rate of $\mathrm{HOBr}$ in the snow interstitial air by the snow grains which can be written as $\mathrm{HOBr}_{(\mathrm{SIA}, i)} \rightarrow \mathrm{HOBr}_{(\text {liquid }, i)}$.

To confirm this finding, we performed a simulation by changing the rate of $\mathrm{HOBr}$ absorption back to the original value while the rates of other reactions keep changed. We found that the simulation results obtained after this change are similar to that shown in Fig. 5. Therefore, we conclude that the volume fraction of LLL heavily controls the HOBr transfer between the snow interstitial air and the snow grains, thus dominating the occurrence of ODEs. In contrast to that, as the change of the LLL volume fraction also affects the rates of the liquid reactions, this simulation test also suggests that the rates of the aqueous reactions have relatively small impacts on the occurrence of ODEs.

\subsubsection{PH Value of Snowpack}

In a third set of model runs, we modified the initial PH value of snowpack from 4 to 7 and 10. The simulation results are shown in the supplementary material. It is found that under the condition $\mathrm{PH}=7$, the temporal behavior of ozone and bromine species is similar to that with $\mathrm{PH}=4$. However, the total bromine amount left in the boundary layer after the complete removal of ozone has a value of only approximately $245 \mathrm{ppt}$ on day 14 compared to the value $(260 \mathrm{ppt})$ with $\mathrm{PH}=4$. This reduced amount of bromine is probably caused by the slow down of the aqueous reactions in LLL of the snowpack. When the PH value increases to 10, the ozone depletion either in the boundary layer or in the snow layers disappears. It denotes that in an alkaline snowpack, the deficit of the $\mathrm{H}^{+}$storage leads to a retardant of the activation of bromide from the snowpack. As a result, the bromine released from an alkaline snowpack is not enough to be responsible for the ozone consumption. The relatively weak bromine release from the snowpack with high PH value has also been presented and discussed by Toyota et al. (2014). To summary, according to the results of the present study, ODEs are more favored above an acidic or a neutral snowpack instead of an alkaline snowpack, which is in consistence with previous findings.

\subsubsection{Snowpack Thickness}

30 In order to perform simulations with the implementation of a snowpack with different thickness, we added or removed a number of snowpack layers in the model so that a $50 \mathrm{~cm}$ snowpack (10 layers) or a $5 \mathrm{~cm}$ snowpack (1 layer) is considered in the model. For a $50 \mathrm{~cm}$ snowpack, three additional snow layers are added to the bottom of the snowpack. It is found that the 
Atmos. Chem. Phys. Discuss., doi:10.5194/acp-2016-553, 2016

Atmospheric

Chemistry

Manuscript under review for journal Atmos. Chem. Phys.

Published: 7 July 2016

(c) Author(s) 2016. CC-BY 3.0 License.

and Physics

Discussions

(c) $\underset{\mathrm{BY}}{\mathrm{B}}$

ozone depletion rates both in the ambient air and in the snow interstitial air are only slightly influenced, which confirms the plausible idea that the layers responsible for the occurrence of ODEs are the snow layers close to the surface. This finding is also in consistence with the results shown in Sect 3.2.1 in which the ozone depletion rate in the ambient air is mostly dependent on the amount of bromine released from the shallow snow layers.

The snowpack thickness is then reduced to $5 \mathrm{~cm}$ by including only one snow layer in the model, and the simulation results are shown in Fig. 7. It is interesting to find that in the snowpack, the complete removal of ozone begins on day 1.6 and finishes on day 3.6, and thus at a similar time scale compared to the standard scenario. However, in the boundary layer, ozone is only partly consumed and remains stable after day 4, with a mixing ratio of approximately 20 ppb. We first focus on the temporal behavior of the chemical species in the snow interstitial air. At the beginning of the simulation, before day 1.6, as ozone either in the ambient air or in the snow interstitial air is abundant, the formation of $\mathrm{BrO}$ and $\mathrm{HOBr}$ in the boundary layer and within the snowpack is favored. As HOBr is involved in the bromine explosion mechanism occurring in the LLL of the snow particles, the bromine amount in the snow interstitial air starts to increase rapidly. As a result, within the time period between day 1.6 and day 3.6, the total bromine level in the snowpack shows an explosive increase, and the depletion of ozone reaches the maximum speed, at approximately $1.8 \mathrm{ppb} \mathrm{h}^{-1}$, until ozone in the interstitial air is completely removed. $\mathrm{The}$ peak value of $\mathrm{Br}_{2}$ in the snowpack is also found at this time, with about 4 ppt. After day 3.6, due to the lack of ozone in the snowpack, BrO and $\mathrm{HOBr}$ mixing ratios show a sharp decrease, reaching the level lower than $1 \mathrm{ppt}$, which extremely slows down the bromine activation from the snow particles. The existing $\mathrm{Br}_{2}$ in the snowpack is released to the boundary layer or photolyzed rapidly in the presence of sunlight, which leads to the disappearance of $\mathrm{Br}_{2}$ after day 4. At the end of the ODE, the bromine containing compounds left in the snow interstitial air are mostly in the form of $\mathrm{HBr}$, which is produced by the absorption of $\mathrm{Br}$ by the aldehydes.

In the boundary layer above the snowpack with the thickness of $5 \mathrm{~cm}$, in the initial period of the ODE (before day 3.6 ), BrO and $\mathrm{HOBr}$ increase as similar as those in the snowpack, which causes a relatively rapid consumption of ozone in the ambient air. However, when the ODE in the snow layer finishes on approximately day 3.6, the release of $\mathrm{Br}_{2}$ from the snowpack is prohibited. Since the HOBr molecules in the ambient air continuously land on the snowpack via the deposition processes, the total bromine amount in the boundary layer keeps dropping during this time period until a near-zero value is attained. As a result of the lack of bromine in the ambient air, the termination of the ozone depletion occurs, and the complete removal of ozone in the boundary layer cannot be achieved.

\subsection{Concentration Sensitivity Analysis of the Mass Transfer between the Ambient Air and the Snowpack}

The local concentration sensitivity is calculated for the reaction mechanism used in the present study. We focus on the relative importance of the steps representing the mass transfer among the ambient air, snow interstitial air and the snow grains for the ozone mixing ratios in the boundary layer and the snow interstitial air. As the computation of the concentration sensitivities requires a multi-step iteration which is rather time-consuming, in the present study, the concentration sensitivity analyses of the gas-phase reactions as well as the aqueous reactions occurring in the LLL of the snow grains are not performed for simplicity. 
Atmos. Chem. Phys. Discuss., doi:10.5194/acp-2016-553, 2016

Manuscript under review for journal Atmos. Chem. Phys.

Published: 7 July 2016

(c) Author(s) 2016. CC-BY 3.0 License.

The relative concentration sensitivity of the reaction steps for the ozone in the boundary layer during the depletion period (on day 3) is shown in Fig. 8. It can be seen that from reactions (R721) to (R727), the relative concentration sensitivity declines with the increase of the reaction number, which is also valid for the reaction groups (R735)-(R741) and (R826)-(R832). It denotes that the ozone mixing ratio in the boundary layer is more dependent on the mass transfer processes in the shallow snow layers rather than those in the deep snow layers at this time stage. This result confirms the finding shown in Sect. 3.2 that the occurrence of the ODE in the ambient air is determined mostly by the snow chemistry occurring in the surface snow layers.

Among the reaction steps in the transfer processes, it is seen from Fig. 8 that the release of $\mathrm{Br}_{2}$ from the snowpack (R826) and the deposition of $\mathrm{HOBr}$ from the ambient air (R721) are the most dominant steps which critically control the mixing ratio of ozone in the boundary layer as they determine the total bromine amount in the ambient air. The values of the concentration sensitivities of these two reactions, (R826) and (R721), reach approximately 0.037 and 0.02 , respectively. Thus, the occurrence of the ODE in the boundary layer is mostly determined by the joint effect of the turbulent mixing, molecular diffusion and wind ventilation. Apart from reactions (R826) and (R721), the scavenging of HOBr by the snow grains, (R735), is also shown as crucial since it heavily influences the release of bromine from the snow grains. Moreover, this scavenging process of $\mathrm{HOBr}$ has a negative concentration sensitivity, which means that the enhancement of the $\mathrm{HOBr}$ uptake by the snow particles tends to accelerate the consumption of ozone in the boundary layer. Due to the dominance of these reaction steps with large concentration sensitivities, it is of importance to have a good knowledge of the transfer rates of these steps in the present ozone depletion mechanism. In contrast to that, according to the low computed sensitivities of reactions (R749)-(R755), although the hydrolysis of $\mathrm{BrONO}_{2}$ causes the formation of the liquid-phase $\mathrm{HOBr}$ and $\mathrm{H}^{+}$ions which may facilitate the release of $\mathrm{Br}_{2}$ from the snow grains, it is indicated in Fig. 8 that the importance of these reactions are negligible for the ozone mixing ratio in the ambient air.

Figure 9 depicts the dependence of the ozone mixing ratios in the snow layers with the depth of $2.5 \mathrm{~cm}$ and $32.5 \mathrm{~cm}$ on each step of the mass transfer processes during the depletion of ozone in the ambient air (on day 3). It can be seen in Fig. 9(a) that in the snow layer close to the ground surface, the determining step for the occurrence of the ODE is the scavenging of $\mathrm{HOBr}$ molecules by the snow particles, (R735). This scavenging process has the largest absolute value of the concentration sensitivity, 0.24 , among the mass transfer processes in computation. Moreover, the concentration sensitivity of (R735) is negative, which is as similar as that for the ozone in the boundary layer. Thus, the speedup of the $\mathrm{HOBr}$ absorption by the snow grains would consequently advance the occurrence of ODEs both in the boundary layer and within the interstitial air of this surface snow layer. This conclusion is also in accordance with the comparison of the onsets of ODEs discussed in Sect. 3.2.1.

Compared to the deep snow layers which are close to the bottom of the snowpack, in the surface snow layer $(\mathrm{depth}=2.5 \mathrm{~cm})$, the deposition of $\mathrm{HOBr}$ as well as the emission of $\mathrm{Br}_{2}$ are relatively fast. Therefore, these two processes, (R721) and (R826), are not the rate-determining steps for the depletion of ozone in the snow interstitial air, and thus have relatively lower sensitivity values compared to (R735) (see Fig. 9(a)). It is also noteworthy that among the HOBr deposition reactions (R721)-(R727), the concentration sensitivities of (R722)-(R727) are positive for the ozone in this snow layer while a negative sensitivity is obtained for (R721). The reason for the different signs of these sensitivities is that reactions (R721)-(R727) are parallel competing reactions. The rate increase of (R721) represents that the deposition of $\mathrm{HOBr}$ on this surface snow layer speeds 
Atmos. Chem. Phys. Discuss., doi:10.5194/acp-2016-553, 2016

Atmospheric

Chemistry

Manuscript under review for journal Atmos. Chem. Phys.

Published: 7 July 2016

(c) Author(s) 2016. CC-BY 3.0 License.

and Physics

Discussions

(c) (i)

up, which eventually accelerates the ozone consumption in this snow layer. In contrast to that, the rate increase of reactions (R722)-(R727) would reduce the amount of $\mathrm{HOBr}$ available for the surface snow layer. As a result, the ozone depletion in this snow layer would be retarded. In addition, by comparing the values of the sensitivities shown in Fig. 8 and Fig. 9(a), it is also seen that the concentration sensitivities for the surface snow layer are larger than those for the ozone in the boundary ayer, which represents that the occurrence of the ODE in the interstitial air of the surface snow is more dependent on the mass transfer between the ambient air and the snowpack compared to the ozone consumption in the boundary layer.

The concentration sensitivity of ozone in the snow layer close to the bottom (depth=32.5 cm) is given in Fig. 9(b). As similar as the situation in the snow layer at the depth of $2.5 \mathrm{~cm}$, the most influential reaction steps for the ozone in this bottom snow layer are the deposition of HOBr from the boundary layer (R727), scavenging of HOBr by snow grains (R741), and the release of $\mathrm{Br}_{2}$ to the ambient air (R832). However, as mentioned above, the snow interstitial air and the snow particles in the deep layers are less accessible. Thus, the mass transfer between the ambient air and this bottom snow layer as well as the quantity of the deposited $\mathrm{HOBr}$ become more critical for controlling the ozone consumption in this snow layer. As a result, it can be seen in Fig. 9(b) that the reactions of the $\mathrm{HOBr}$ deposition (R727) and the $\mathrm{Br}_{2}$ emission (R832) in the present reaction mechanism are relatively more important than those for the ozone in the surface snow layer which are shown in Fig. 9(a). Besides, in this bottom snow layer (depth=32.5 cm), as the quantity of the deposited HOBr from the boundary layer is less than the amount of $\mathrm{HOBr}$ landing on the surface snow layer, the reaction with the involvement of $\mathrm{BrONO}_{2},(\mathrm{R} 755)$, shows considerable sensitivity for the mixing ratio of ozone, which denotes that in this bottom snow layer, the hydrolysis of $\mathrm{BrONO}_{2}$ also contributes partly to the ozone loss. At last, by comparing Fig. 9(a) and (b), it should also be noticed that the concentration sensitivities of the mass transfer steps for the ozone in the present bottom snow layer are lower than those in the surface snow layer, which means that the ozone at the bottom of the snowpack is less influenced by the whole mass exchange system between the ambient air and the snowpack. We speculate that the temporal evolution of ozone in this snow layer is probably dominated by the gas-phase bromine reactions occurring within the snow interstitial air at this depth.

Figure 10 displays the relative importance of each step in the reaction mechanism for the ambient ozone mixing ratio within the time periods before the occurrence of ODE (on day 2) and after the complete removal of ozone (on day 10). By comparing the present results shown in Fig. 10(a) with those displayed in Fig. 8, it can be found that before the occurrence of ODE, the mechanisms which control the mixing ratio of ozone in the boundary layer the most are the deposition of $\mathrm{HOBr}$ onto the snowpack (R721), scavenging of HOBr by the snow particles (R735), and the release of $\mathrm{Br}_{2}$ to the ambient air (R826), which is similar to the situation during the depletion of ozone. However, the sensitivity values of these steps before the ODE are significantly smaller than those during the consumption of ozone which are depicted in Fig. 8. This is not entirely unexpected since these mass transfer steps begin to significantly affect the temporal behavior of ozone in the ambient air after the start of ODE.

After the complete consumption of ozone in the boundary layer, the dependence of the ozone mixing ratio on the mass transfer processes varies with time (see Fig. 10(b)). It can be seen that during this time period (on day 10), as the bromine in the interstitial air of the surface snow layers (depth $<22.5 \mathrm{~cm}$ ) exist mostly in the form of $\mathrm{HBr}$ which has only slight influence on the ozone loss, the bromine transfer processes between the surface snow layer and the ambient air, (R721), (R735) and (R826), 
Atmos. Chem. Phys. Discuss., doi:10.5194/acp-2016-553, 2016

Manuscript under review for journal Atmos. Chem. Phys.

which used to be dominant before and during the ODE are no longer important for the ozone mixing ratio in the boundary layer. The concentration sensitivities of these reactions are lower than $5 \times 10^{-4}$ in this time period. In contrast to that, in the snow layer with the depth of $22.5 \mathrm{~cm}$ (the fifth snow layer in Fig. 10(b)), due to the presence of ozone, the auto-catalytic reaction cycle of bromine and the bromine explosion mechanism are still able to proceed, which forms a considerable quantity of active bromine species such as $\mathrm{Br}_{2}$. The formed $\mathrm{Br}_{2}$ is then carried to the boundary layer, consequently reducing the mixing ratio of ozone in the ambient air. Therefore, the release of $\mathrm{Br}_{2}$ from the snow layer with the depth of $22.5 \mathrm{~cm}$, (R830), has the largest absolute value of the concentration sensitivity for the ozone in the boundary layer (see Fig. 10(b)). Aside from this reaction, the scavenging of HOBr by the snow grains in this layer, (R739), is also crucial as it is the determining step of the bromine explosion mechanism in this snow layer. In addition, reaction (R721) still possesses a considerable value of the concentration sensitivity as it is the major pathway of the bromine loss in the ambient air during this time period.

\section{Conclusions and Future Developments}

In the present study, the influences on ODEs either in the boundary layer or within the snowpack caused by the change of the snowpack properties are simulated and analyzed. In order to better describe the physicochemical processes occurring within the snowpack, a snowpack module which is able to depict the mass exchange between the ambient air and the snowpack is developed and implemented in a box model. A reaction mechanism with the involvement of bromine species is applied for the estimation of the chemical production and consumption occurring in the boundary layer and within the interstitial air of the snowpack. The temporal and spatial distributions of ozone and principal bromine species in the ambient air and within the snowpack are captured and discussed. It is found that above a snowpack with a grain diameter of $1 \mathrm{~mm}$, the depletion of ozone in surface snow layers is faster than that in the boundary layer, causing a positive ozone gradient close to the ground. The simulated mixing ratios of $\mathrm{BrO}$ and $\mathrm{Br}_{2}$ are found within the range of 20-60 ppt and 2-12 ppt respectively, similar to values reported from field observations. The vertical distribution of $\mathrm{Br}_{2}$ within the snowpack is also obtained and compared with previous studies.

By varying the snowpack properties, we found that the diameter of snow grains, volume fraction of the LLL, and the uptake rate of $\mathrm{HOBr}$ by snow particles are the deterministic factors which critically control the occurrence of ODEs in the polar boundary layer. After the reduction of the snow grain diameters, it is found that ODEs both in the boundary layer and within the surface snow layers are accelerated while the consumptions of ozone in deeper snow layers are retarded. The reason is attributable to the faster $\mathrm{HOBr}$ deposition from the boundary layer onto these surface snow layers. Conversely, increasing the snow grain size leads to no ODE occurrence, thus we conclude that our simulations indicate the snow grain size (or specific surface area) to be a critical parameter in bromine activation and the occurrence of ODEs. The liquid-like layer volume fraction is also shown to be an important parameter for the depletion of ozone as the reduction of LLL volume fraction tends to prohibit ODEs. The simulation test shows that the reduction of the LLL fraction leads to a strong retardant of the HOBr uptake by snow particles, which determines the occurrence of ODEs. By changing the initial PH value of the snowpack, we found that the complete removal of ozone in the boundary layer is able to proceed above an acidic or a neutral snowpack, however not over 
Atmos. Chem. Phys. Discuss., doi:10.5194/acp-2016-553, 2016

Manuscript under review for journal Atmos. Chem. Phys.

Published: 7 July 2016

(c) Author(s) 2016. CC-BY 3.0 License.
Atmospheric

Chemistry

and Physics

Discussions

(c) (1)

an alkaline type snowpack. Thicknesses of the snowpack were also investigated in the present model by adding or removing several snow layers to the original $35 \mathrm{~cm}$ snowpack. It is found that the depletion of ozone in the boundary layer depends more heavily on the snow chemistry occurring in the surface snow layers rather than in the deep snow layers.

The concentration sensitivity analysis helps to clarify the relative importance of each step in the mass transfer between the

5 boundary layer and the snowpack. During the depletion of ozone, the deposition of $\mathrm{HOBr}$ onto the snowpack, release of $\mathrm{Br}_{2}$ from the surface snow layers, and the scavenging of $\mathrm{HOBr}$ in the interstitial air by snow grains are shown as the most influential steps for the ozone change in the boundary layer. In contrast, the concentration sensitivity analysis of ozone in the interstitial air of the surface snow layer suggests that the importance of the reaction steps, $\mathrm{HOBr}$ deposition and $\mathrm{Br}_{2}$ release, , becomes lower, which highlights the dominant role of the scavenging of $\mathrm{HOBr}$ in this snow layer. For deeper snow layers. the temporal change of ozone is found to be less dependent on the whole system of the mass transfer between the boundary layer and the snowpack. By conducting the concentration sensitivity analysis at different time points, it is also revealed that the mass transfer processes play the biggest role during the rapid decline of ozone rather than in the time periods before or after the ODE.

Although the important role of the snowpack in the depletion of ozone in Arctic is clearly indicated and well described in the KINAL-SNOW model, the present model stll has some potential for improvement. For instance, the mass transfer between different snow layers should be considered in the future. A better parameterization of the LLL in the surface of snow grains such as the method proposed by Kuo et al. (2011) is also helpful for clarifying the dominant role of the LLL quantitatively. Moreover, an extension of the present model to 1-D is straightforward after introducing the mass exchange between different layers and a precise parameterization of the vertical distribution of the turbulent diffusivity. At present, the authors are adding the snowpack module to a recently developed 1-D model KINAL-T (Cao et al., 2016), aiming to elucidate more mechanistic details of ODEs occurring above the snowpack.

Acknowledgements. This work was supported by the National Natural Science Foundation of China (No. 41375044), the Natural Science Foundation of Jiangsu Province (No. 2015s042), the Double Innovation Talent Program (No. R2015SCB02), the Polar Strategic Foundation (No. 20150308) and the Startup Foundation for Introducing Talent of NUIST (No. 2014r066). The authors also like to thank the support from NUIST for providing the High Performance Computing (HPC) platform for the computation of the concentration sensitivities of the reaction mechanism. 
Atmos. Chem. Phys. Discuss., doi:10.5194/acp-2016-553, 2016

Atmospheric

Chemistry

Published: 7 July 2016

(c) Author(s) 2016. CC-BY 3.0 License.

and Physics

Discussions

(c) (i)

\section{References}

Abbatt, J. P. D., Thomas, J. L., Abrahamsson, K., Boxe, C., Granfors, A., Jones, A. E., King, M. D., Saiz-Lopez, A., Shepson, P. B., Sodeau, J., Toohey, D. W., Toubin, C., von Glasow, R., Wren, S. N., and Yang, X.: Halogen activation via interactions with environmental ice and snow in the polar lower troposphere and other regions, Atmos. Chem. Phys., 12, 6237-6271, doi:10.5194/acp-12-6237-2012, 2012.

5 Albert, M. R. and Shultz, E. F.: Snow and firn properties and air-snow transport processes at Summit, Greenland, Atmos. Environ., 36, 2789-2797, doi:http://dx.doi.org/10.1016/S1352-2310(02)00119-X, 2002.

Andreas, E. L., Jordan, R. E., and Makshtas, A. P.: Simulations of snow, ice, and near-surface atmospheric processes on Ice Station Weddell, J. Hydrometeorol., 5, 611-624, doi:10.1175/1525-7541(2004)005<0611:SOSIAN>2.0.CO;2, 2004.

Atkinson, R., Baulch, D. L., Cox, R. A., Crowley, J. N., Hampson, R. F., Hynes, R. G., Jenkin, M. E., Kerr, J. A., Rossi, M., and Troe, J.: Summary of evaluated kinetic and photochemical data for atmospheric chemistry, Tech. rep., 2006.

Barrie, L. A., Bottenheim, J. W., Schnell, R. C., Crutzen, P. J., and Rasmussen, R. A.: Ozone destruction and photochemical reactions at polar sunrise in the lower Arctic atmosphere, Nature, 334, 138-141, doi:10.1038/334138a0, 1988.

Barrie, L. A., Bottenheim, J. W., and Hart, W. R.: Polar Sunrise Experiment 1992 (PSE 1992): Preface, J. Geophys. Res. Atmos., 99, 25 313-25 314, doi:10.1029/94JD01929, 1994.

Beare, R., Macvean, M., Holtslag, A., Cuxart, J., Esau, I., Golaz, J.-C., Jimenez, M., Khairoutdinov, M., Kosovic, B., Lewellen, D., Lund, T., Lundquist, J., Mccabe, A., Moene, A., Noh, Y., Raasch, S., and Sullivan, P.: An intercomparison of large-eddy simulations of the stable boundary layer, Boundary Layer Meteorol., 118, 247-272, doi:10.1007/s10546-004-2820-6, 2006.

Beckwith, R. C., Wang, T. X., and Margerum, D. W.: Equilibrium and kinetics of bromine hydrolysis, Inorg. Chem., 35, 995-1000, doi:10.1021/ic950909w, 1996.

20 Bottenheim, J., Gallant, A., and Brice, K.: Measurements of $\mathrm{NO}_{\mathrm{Y}}$ species and $\mathrm{O}_{3}$ at $82^{\circ} \mathrm{N}$ latitude, Geophys. Res. Lett., 13, 113-116, doi:10.1029/GL013i002p00113, 1986.

Cao, L. and Gutheil, E.: Numerical simulation of tropospheric ozone depletion in the polar spring, Air Qual. Atmos. Health, 6, 673-686, doi:10.1007/s11869-013-0208-9, 2013.

Cao, L., Sihler, H., Platt, U., and Gutheil, E.: Numerical analysis of the chemical kinetic mechanisms of ozone depletion and halogen release in the polar troposphere, Atmos. Chem. Phys., 14, 3771-3787, doi:10.5194/acp-14-3771-2014, 2014.

Cao, L., Platt, U., and Gutheil, E.: Role of the boundary layer in the occurrence and termination of the tropospheric ozone depletion events in polar spring, Atmos. Environ., 132, 98-110, doi:http://dx.doi.org/10.1016/j.atmosenv.2016.02.034, 2016.

Chance, K.: Analysis of BrO measurements from the Global Ozone Monitoring Experiment, Geophys. Res. Lett., 25, 3335-3338, doi:10.1029/98GL52359, 1998.

30 Cunningham, J. and Waddington, E. D.: Air flow and dry deposition of non-sea salt sulfate in polar firn: Paleoclimatic implications, Atmos. Environ., 27, 2943-2956, doi:10.1016/0960-1686(93)90327-U, 1993.

Evans, M. J., Jacob, D. J., Atlas, E., Cantrell, C. A., Eisele, F., Flocke, F., Fried, A., Mauldin, R. L., Ridley, B. A., Wert, B., Talbot, R., Blake, D., Heikes, B., Snow, J., Walega, J., Weinheimer, A. J., and Dibb, J.: Coupled evolution of $\mathrm{BrO}_{\mathrm{x}}-\mathrm{ClO}_{\mathrm{x}}-\mathrm{HO}_{\mathrm{x}}-\mathrm{NO}_{\mathrm{x}}$ chemistry during bromine-catalyzed ozone depletion events in the arctic boundary layer, J. Geophys. Res. Atmos., 108, doi:10.1029/2002JD002732, 2003.

35 Fan, S.-M. and Jacob, D. J.: Surface ozone depletion in Arctic spring sustained by bromine reactions on aerosols, Nature, 359, 522-524, doi:10.1038/359522a0, 1992.

Faraday, M.: Experimental researches in chemistry and physics, Tailor and Francis, 1859. 
Atmos. Chem. Phys. Discuss., doi:10.5194/acp-2016-553, 2016

Manuscript under review for journal Atmos. Chem. Phys.

Published: 7 July 2016

(c) Author(s) 2016. CC-BY 3.0 License.
Atmospheric

Chemistry

and Physics

Discussions

(c)

Finlayson-Pitts, B. J. and Pitts, J. N.: Chemistry of upper and lower atmosphere: theory, experiments, and applications, Academic Press, 2000.

Foster, K. L., Plastridge, R. A., Bottenheim, J. W., Shepson, P. B., Finlayson-Pitts, B. J., and Spicer, C. W.: The role of Br 2 and BrCl in surface ozone destruction at polar sunrise, Science, 291, 471-474, 2001.

5 Frieß, U., Hollwedel, J., König-Langlo, G., Wagner, T., and Platt, U.: Dynamics and chemistry of tropospheric bromine explosion events in the Antarctic coastal region, J. Geophys. Res. Atmos., 109, doi:10.1029/2003JD004133, 2004.

Galbally, I. and Allison, I.: Ozone fluxes over snow surfaces, J. Geophys. Res., 77, 3946-3949, 1972.

Gottwald, B. A. and Wanner, G.: A reliable rosenbrock integrator for stiff differential equations, Computing, 26, 355-360, doi:10.1007/BF02237954, 1981.

Grannas, A. M., Jones, A. E., Dibb, J., Ammann, M., Anastasio, C., Beine, H. J., Bergin, M., Bottenheim, J., Boxe, C. S., Carver, G., Chen, G., Crawford, J. H., Dominé, F., Frey, M. M., Guzmán, M. I., Heard, D. E., Helmig, D., Hoffmann, M. R., Honrath, R. E., Huey, L. G., Hutterli, M., Jacobi, H. W., Klán, P., Lefer, B., McConnell, J., Plane, J., Sander, R., Savarino, J., Shepson, P. B., Simpson, W. R., Sodeau, J. R., von Glasow, R., Weller, R., Wolff, E. W., and Zhu, T.: An overview of snow photochemistry: evidence, mechanisms and impacts, Atmos. Chem. Phys., 7, 4329-4373, doi:10.5194/acp-7-4329-2007, 2007.

15 Halfacre, J. W., Knepp, T. N., Shepson, P. B., Thompson, C. R., Pratt, K. A., Li, B., Peterson, P. K., Walsh, S. J., Simpson, W. R., and Matrai, P. A.: Temporal and spatial characteristics of ozone depletion events from measurements in the Arctic, Atmos. Chem. Phys., 14, 4875-4894, 2013.

Hanson, D. R., Ravishankara, A. R., and Solomon, S.: Heterogeneous reactions in sulfuric acid aerosols: A framework for model calculations, J. Geophys. Res. Atmos., 99, 3615-3629, doi:10.1029/93JD02932, 1994.

Hausmann, M. and Platt, U.: Spectroscopic measurement of bromine oxide and ozone in the high Arctic during Polar Sunrise Experiment 1992, J. Geophys. Res. Atmos., 99, 25 399-25 413, doi:10.1029/94JD01314, 1994.

Helmig, D., Bocquet, F., Cohen, L., and Oltmans, S. J.: Ozone uptake to the polar snowpack at Summit, Greenland, Atmos. Environ., 41, 5061-5076, doi:10.1016/j.atmosenv.2006.06.064, 2007a.

Helmig, D., Ganzeveld, L., Butler, T., and Oltmans, S. J.: The role of ozone atmosphere-snow gas exchange on polar, boundary-layer tropospheric ozone - a review and sensitivity analysis, Atmos. Chem. Phys., 7, 15-30, doi:10.5194/acp-7-15-2007, 2007b.

Helmig, D., Oltmans, S. J., Carlson, D., Lamarque, J.-F., Jones, A., Labuschagne, C., Anlauf, K., and Hayden, K.: A review of surface ozone in the polar regions, Atmos. Environ., 41, 5138-5161, doi:http://dx.doi.org/10.1016/j.atmosenv.2006.09.053, 2007c.

Helmig, D., Boylan, P., Johnson, B., Oltmans, S., Fairall, C., Staebler, R., Weinheimer, A., Orlando, J., Knapp, D. J., Montzka, D. D., Flocke, F., Frieß, U., Sihler, H., and Shepson, P. B.: Ozone dynamics and snow-atmosphere exchanges during ozone depletion events at Barrow, Alaska, J. Geophys. Res. Atmos., 117, doi:10.1029/2012JD017531, 2012.

Hönninger, G. and Platt, U.: Observations of $\mathrm{BrO}$ and its vertical distribution during surface ozone depletion at Alert, Atmos. Environ., 36, 2481-2489, doi:http://dx.doi.org/10.1016/S1352-2310(02)00104-8, 2002.

Huff, A. K. and Abbatt, J. P. D.: Gas-phase $\mathrm{Br}_{2}$ production in heterogeneous reactions of $\mathrm{Cl}_{2}, \mathrm{HOCl}$, and $\mathrm{BrCl}$ with halide-ice surfaces, J. Phys. Chem. A, 104, 7284-7293, doi:10.1021/jp001155w, 2000.

Huff, A. K. and Abbatt, J. P. D.: Kinetics and product yields in the heterogeneous reactions of $\mathrm{HOBr}$ with ice surfaces containing NaBr and $\mathrm{NaCl}$, J. Phys. Chem. A, 106, 5279-5287, doi:10.1021/jp014296m, 2002.

Impey, G., Mihele, C., Anlauf, K., Barrie, L., Hastie, D., and Shepson, P.: Measurements of photolyzable halogen compounds and bromine radicals during the polar sunrise experiment 1997, J. Atmos. Chem., 34, 21-37, doi:10.1023/A:1006264912394, 1999. 
Atmos. Chem. Phys. Discuss., doi:10.5194/acp-2016-553, 2016

Manuscript under review for journal Atmos. Chem. Phys.

Published: 7 July 2016

(c) Author(s) 2016. CC-BY 3.0 License.
Atmospheric

Chemistry

and Physics

Discussions

(c) (i)

Impey, G. A., Shepson, P. B., Hastie, D. R., Barrie, L. A., and Anlauf, K. G.: Measurements of photolyzable chlorine and bromine during the Polar Sunrise Experiment 1995, J. Geophys. Res. Atmos., 1021, 16 005-16 010, 1997.

Jacobi, H.-W., Frey, M. M., Hutterli, M. A., Bales, R. C., Schrems, O., Cullen, N. J., Steffen, K., and Koehler, C.: Measurements of hydrogen peroxide and formaldehyde exchange between the atmosphere and surface snow at Summit, Greenland, Atmos. Environ., 36, 2619-2628, doi:10.1016/S1352-2310(02)00106-1, 2002.

Jones, A. E., Weller, R., Wolff, E. W., and Jacobi, H. W.: Speciation and rate of photochemical NO and $\mathrm{NO}_{2}$ production in Antarctic snow, Geophys. Res. Lett., 27, 345-348, doi:10.1029/1999GL010885, 2000.

Jones, A. E., Weller, R., Anderson, P. S., Jacobi, H.-W., Wolff, E. W., Schrems, O., and Miller, H.: Measurements of $\mathrm{NO}_{\mathrm{x}}$ emissions from the Antarctic snowpack, Geophys. Res. Lett., 28, 1499-1502, doi:10.1029/2000GL011956, 2001.

Jones, A. E., Anderson, P. S., Wolff, E. W., Turner, J., Rankin, A. M., and Colwell, S. R.: A role for newly forming sea ice in springtime polar tropospheric ozone loss? Observational evidence from Halley station, Antarctica, J. Geophys. Res. Atmos., 111, doi:10.1029/2005JD006566, 2006.

Jones, A. E., Anderson, P. S., Begoin, M., Brough, N., Hutterli, M. A., Marshall, G. J., Richter, A., Roscoe, H. K., and Wolff, E. W.: BrO, blizzards, and drivers of polar tropospheric ozone depletion events, Atmos. Chem. Phys., 9, 4639-4652, doi:10.5194/acp-9-4639-2009, 2009.

Jones, A. E., Anderson, P. S., Wolff, E. W., Roscoe, H. K., Marshall, G. J., Richter, A., Brough, N., and Colwell, S. R.: Vertical structure of Antarctic tropospheric ozone depletion events: characteristics and broader implications, Atmos. Chem. Phys., 10, 7775-7794, doi:10.5194/acp-10-7775-2010, 2010.

King, M. D. and Simpson, W. R.: Extinction of UV radiation in Arctic snow at Alert, Canada (82 N), J. Geophys. Res. Atmos., 106, $12499-$ 12 507, doi:10.1029/2001JD900006, 2001.

Kreher, K., Johnston, P. V., Wood, S. W., Nardi, B., and Platt, U.: Ground-based measurements of tropospheric and stratospheric BrO at Arrival Heights, Antarctica, Geophys. Res. Lett., 24, 3021-3024, doi:10.1029/97GL02997, 1997.

Kuo, M. H., Moussa, S. G., and McNeill, V. F.: Modeling interfacial liquid layers on environmental ices, Atmos. Chem. Phys., 11, 9971-9982, doi:10.5194/acp-11-9971-2011, 2011.

Langendörfer, U., Lehrer, E., Wagenbach, D., and Platt, U.: Observation of filterable bromine variabilities during arctic tropospheric ozone depletion events in high (1 hour) time resolution, J. Atmos. Chem., 34, 39-54, doi:10.1023/A:1006217001008, 1999.

Lehrer, E., Hönninger, G., and Platt, U.: A one dimensional model study of the mechanism of halogen liberation and vertical transport in the polar troposphere, Atmos. Chem. Phys., 4, 2427-2440, doi:10.5194/acp-4-2427-2004, 2004.

Liao, J., Huey, L. G., Tanner, D. J., Flocke, F. M., Orlando, J. J., Neuman, J. A., Nowak, J. B., Weinheimer, A. J., Hall, S. R., Smith, J. N., Fried, A., Staebler, R. M., Wang, Y., Koo, J.-H., Cantrell, C. A., Weibring, P., Walega, J., Knapp, D. J., Shepson, P. B., and Stephens, C. R.: Observations of inorganic bromine ( $\mathrm{HOBr}, \mathrm{BrO}$, and $\mathrm{Br}_{2}$ ) speciation at Barrow, Alaska, in spring 2009, J. Geophys. Res. Atmos., 117, doi:10.1029/2011JD016641, 2012.

Liao, W. and Tan, D.: 1-D Air-snowpack modeling of atmospheric nitrous acid at South Pole during ANTCI 2003, Atmos. Chem. Phys., 8, 7087-7099, 2008.

35 Michalowski, B. A., Francisco, J. S., Li, S.-M., Barrie, L. A., Bottenheim, J. W., and Shepson, P. B.: A computer model study of multiphase chemistry in the Arctic boundary layer during polar sunrise, J. Geophys. Res. Atmos., 105, 15 131-15 145, doi:10.1029/2000JD900004, 2000 . 
Atmos. Chem. Phys. Discuss., doi:10.5194/acp-2016-553, 2016

Atmospheric

Chemistry

Manuscript under review for journal Atmos. Chem. Phys.

Published: 7 July 2016

(c) Author(s) 2016. CC-BY 3.0 License.

and Physics

Discussions

(c) $\underset{\mathrm{By}}{\mathrm{i}}$

Morin, S., Marion, G. M., von Glasow, R., Voisin, D., Bouchez, J., and Savarino, J.: Precipitation of salts in freezing seawater and ozone depletion events: a status report, Atmos. Chem. Phys., 8, 7317-7324, doi:10.5194/acp-8-7317-2008, 2008.

Oltmans, S. J.: Surface ozone measurements in clean air, J. Geophys. Res. Oceans, 86, 1174-1180, doi:10.1029/JC086iC02p01174, 1981.

Platt, U. and Hönninger, G.: The role of halogen species in the troposphere, Chemosphere, 52, 325-338, doi:http://dx.doi.org/10.1016/S00456535(03)00216-9, 2003.

Platt, U. and Wagner, T.: Satellite mapping of enhanced BrO concentrations in the troposphere, Nature, 395, 486-490, doi:10.1038/26723, 1998.

Richter, A., Wittrock, F., Eisinger, M., and Burrows, J. P.: GOME observations of tropospheric BrO in northern hemispheric spring and summer 1997, Geophys. Res. Lett., 25, 2683-2686, doi:10.1029/98GL52016, 1998.

Röth, E. P.: A fast algorithm to calculate the photonflux in optically dense media for use in photochemical models, Berichte der Bunsengesellschaft für physikalische Chemie, 96, 417-420, doi:10.1002/bbpc.19920960335, 1992.

Röth, E. P.: Description of the anisotropic radiation transfer model ART to dermine photodissociation coefficients, vol. 3960, Forschungszentrum, Zentralbibliothek, Jülich, 2002.

Saiz-Lopez, A., Plane, J. M. C., Mahajan, A. S., Anderson, P. S., Bauguitte, S. J.-B., Jones, A. E., Roscoe, H. K., Salmon, R. A., Bloss, W. J., Lee, J. D., and Heard, D. E.: On the vertical distribution of boundary layer halogens over coastal Antarctica: implications for $\mathrm{O}_{3}$, $\mathrm{HO}_{\mathrm{x}}$, $\mathrm{NO}_{\mathrm{x}}$ and the Hg lifetime, Atmos. Chem. Phys., 8, 887-900, doi:10.5194/acp-8-887-2008, 2008.

Sander, R. and Crutzen, P. J.: Model study indicating halogen activation and ozone destruction in polluted air masses transported to the sea, J. Geophys. Res. Atmos., 101, 9121-9138, doi:10.1029/95JD03793, 1996.

Sander, R. and Morin, S.: Introducing the bromide/alkalinity ratio for a follow-up discussion on "Precipitation of salts in freezing seawater and ozone depletion events: a status report", by Morin et al., published in Atmos. Chem. Phys., 8, 7317-7324, 2008, Atmos. Chem. Phys., 10, 7655-7658, doi:10.5194/acp-10-7655-2010, 2010.

Sander, R., Burrows, J., and Kaleschke, L.: Carbonate precipitation in brine - a potential trigger for tropospheric ozone depletion events, Atmos. Chem. Phys., 6, 4653-4658, doi:10.5194/acp-6-4653-2006, 2006.

Schoenbein, C. F.: Recherche sur la nature de l'odeur qui se manifeste dans certaines actions chimiques, Comptes Redus des Seances Paris, 1840.

Schwartz, S.: Mass-transport considerations pertinent to aqueous phase reactions of gases in liquid-water clouds, in: Chemistry of Multiphase Atmospheric Systems, edited by Jaeschke, W., vol. 6, pp. 415-471, Springer Berlin Heidelberg, doi:10.1007/978-3-642-70627-1_16, 1986.

Simpson, W. R., von Glasow, R., Riedel, K., Anderson, P., Ariya, P., Bottenheim, J., Burrows, J., Carpenter, L. J., Frieß, U., Goodsite, M. E., Heard, D., Hutterli, M., Jacobi, H.-W., Kaleschke, L., Neff, B., Plane, J., Platt, U., Richter, A., Roscoe, H., Sander, R., Shepson, P., Sodeau, J., Steffen, A., Wagner, T., and Wolff, E.: Halogens and their role in polar boundary-layer ozone depletion, Atmos. Chem. Phys., 7, 4375-4418, doi:10.5194/acp-7-4375-2007, 2007.

Stull, R. B.: An introduction to boundary layer meteorology, Kluwer Academic Publishers, The Netherlands, 1988.

Tang, T. and McConnell, J. C.: Autocatalytic release of bromine from Arctic snow pack during polar sunrise, Geophys. Res. Lett., 23, 2633-2636, doi:10.1029/96GL02572, 1996.

35 Thomas, J. L., Stutz, J., Lefer, B., Huey, L. G., Toyota, K., Dibb, J. E., and von Glasow, R.: Modeling chemistry in and above snow at Summit, Greenland - Part 1: Model description and results, Atmos. Chem. Phys., 11, 4899-4914, doi:10.5194/acp-11-4899-2011, 2011. 
Atmos. Chem. Phys. Discuss., doi:10.5194/acp-2016-553, 2016

Manuscript under review for journal Atmos. Chem. Phys.

Published: 7 July 2016

(c) Author(s) 2016. CC-BY 3.0 License.
Atmospheric

Chemistry

and Physics

Discussions

Thomas, J. L., Dibb, J. E., Huey, L. G., Liao, J., Tanner, D., Lefer, B., von Glasow, R., and Stutz, J.: Modeling chemistry in and above snow at Summit, Greenland - Part 2: Impact of snowpack chemistry on the oxidation capacity of the boundary layer, Atmos. Chem. Phys., 12, 6537-6554, doi:10.5194/acp-12-6537-2012, 2012.

Toom-Sauntry, D. and Barrie, L. A.: Chemical composition of snowfall in the high Arctic: 1990-1994, Atmos. Environ., 36, 2683-2693, doi:10.1016/S1352-2310(02)00115-2, 2002.

Toyota, K., McConnell, J. C., Lupu, A., Neary, L., McLinden, C. A., Richter, A., Kwok, R., Semeniuk, K., Kaminski, J. W., Gong, S.-L., Jarosz, J., Chipperfield, M. P., and Sioris, C. E.: Analysis of reactive bromine production and ozone depletion in the Arctic boundary layer using 3-D simulations with GEM-AQ: inference from synoptic-scale patterns, Atmos. Chem. Phys., 11, 3949-3979, doi:10.5194/acp-113949-2011, 2011.

10 Toyota, K., McConnell, J. C., Staebler, R. M., and Dastoor, A. P.: Air-snowpack exchange of bromine, ozone and mercury in the springtime Arctic simulated by the 1-D model PHANTAS - Part 1: In-snow bromine activation and its impact on ozone, Atmos. Chem. Phys., 14, 4101-4133, doi:10.5194/acp-14-4101-2014, 2014.

Tuckermann, M., Ackermann, R., Gölz, C., Lorenzen-Schmidt, H., Senne, T., Stutz, J., Trost, B., Unold, W., and Platt, U.: DOAS-observation of halogen radical-catalysed arctic boundary layer ozone destruction during the ARCTOC-campaigns 1995 and 1996 in Ny-Ålesund, Spitsbergen, Tellus B, 49, 533-555, doi:10.1034/j.1600-0889.49.issue5.9.x, 1997.

Turanyi, T.: KINAL - a program package for kinetic analysis of reaction mechanisms., Comput. Chem., 14, 253-254, 1990.

Valko, P. and Vajda, S.: An extended ODE solver for sensitivity calculations, Comput. Chem., 8, 255-271, doi:http://dx.doi.org/10.1016/0097-8485(84)85017-2, 1984.

Wagner, T., Leue, C., Wenig, M., Pfeilsticker, K., and Platt, U.: Spatial and temporal distribution of enhanced boundary layer BrO concentrations measured by the GOME instrument aboard ERS-2, J. Geophys. Res. Atmos., 106, 24 225-24 235, doi:10.1029/2000JD000201, 2001.

Wagner, T., Ibrahim, O., Sinreich, R., Frieß, U., von Glasow, R., and Platt, U.: Enhanced tropospheric BrO over Antarctic sea ice in mid winter observed by MAX-DOAS on board the research vessel Polarstern, Atmos. Chem. Phys., 7, 3129-3142, doi:10.5194/acp-7-31292007, 2007.

Wang, T. X., Kelley, M. D., Cooper, J. N., Beckwith, R. C., and Margerum, D. W.: Equilibrium, kinetic, and UV-spectral characteristics of aqueous bromine chloride, bromine, and chlorine species, Inorg. Chem., 33, 5872-5878, doi:10.1021/ic00103a040, 1994.

Yang, X., Pyle, J. A., and Cox, R. A.: Sea salt aerosol production and bromine release: Role of snow on sea ice, Geophys. Res. Lett., 35, doi:10.1029/2008GL034536, 2008.

Yang, X., Pyle, J. A., Cox, R. A., Theys, N., and Van Roozendael, M.: Snow-sourced bromine and its implications for polar tropospheric ozone, Atmos. Chem. Phys., 10, 7763-7773, doi:10.5194/acp-10-7763-2010, 2010.

Zeller, K.: Wintertime ozone fluxes and profiles above a subalpine spruce-fir forest, J. Appl. Meteorol., 39, 92-101, doi:10.1175/15200450(2000)039<0092:WOFAPA>2.0.CO;2, 2000.

Zeller, K. and Hehn, T.: Measurements of upward turbulent ozone fluxes above a subalpine spruce-fir forest, Geophys. Res. Lett., 23, 841$844,1996$.

Zeng, T., Wang, Y., Chance, K., Browell, E. V., Ridley, B. A., and Atlas, E. L.: Widespread persistent near-surface ozone depletion at northern high latitudes in spring, Geophys. Res. Lett., 30, doi:10.1029/2003GL018587, 2003.

Zeng, T., Wang, Y., Chance, K., Blake, N., Blake, D., and Ridley, B.: Halogen-driven low-altitude $\mathrm{O}_{3}$ and hydrocarbon losses in spring at northern high latitudes, J. Geophys. Res. Atmos., 111, doi:10.1029/2005JD006706, 2006. 
Atmos. Chem. Phys. Discuss., doi:10.5194/acp-2016-553, 2016

Manuscript under review for journal Atmos. Chem. Phys.

Published: 7 July 2016

(c) Author(s) 2016. CC-BY 3.0 License.

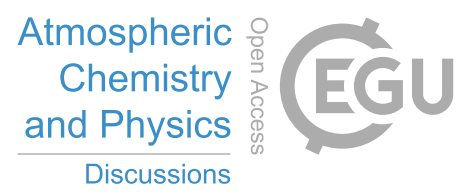

(c) (1)

Zhao, T. L., Gong, S. L., Bottenheim, J. W., McConnell, J. C., Sander, R., Kaleschke, L., Richter, A., Kerkweg, A., Toyota, K., and Barrie,

L. A.: A three-dimensional model study on the production of BrO and Arctic boundary layer ozone depletion, J. Geophys. Res. Atmos., 113, doi:10.1029/2008JD010631, 2008. 
Atmos. Chem. Phys. Discuss., doi:10.5194/acp-2016-553, 2016

Manuscript under review for journal Atmos. Chem. Phys.

Published: 7 July 2016

(c) Author(s) 2016. CC-BY 3.0 License.

Table 1. Aqueous reactions implemented in the KINAL-SNOW model.

\begin{tabular}{lccc}
\hline Reaction & Rate Constant $\left[(\mathrm{L} / \mathrm{mol})^{n-1} \mathrm{~s}^{-1}\right]$ & Order $n$ & Reference \\
\hline $\mathrm{HOBr}+\mathrm{H}^{+}+\mathrm{Br}^{-} \longrightarrow \mathrm{Br}_{2}+\mathrm{H}_{2} \mathrm{O}$ & $4.41 \times 10^{-32}$ & 3 & Beckwith et al. (1996) \\
$\mathrm{Br} 2 \longrightarrow \mathrm{HOBr}+\mathrm{H}^{+}+\mathrm{Br}^{-}$ & $9.70 \times 10^{1}$ & 1 & Beckwith et al. (1996) \\
$\mathrm{HOBr}+\mathrm{H}^{+}+\mathrm{Cl}^{-} \longrightarrow \mathrm{BrCl}+\mathrm{H}_{2} \mathrm{O}$ & $1.55 \times 10^{-32}$ & 3 & Wang et al. (1994) \\
$\mathrm{BrCl} \longrightarrow \mathrm{HOBr}+\mathrm{H}^{+}+\mathrm{Cl}^{-}$ & $1.00 \times 10^{5}$ & 1 & Wang et al. (1994) \\
$\mathrm{BrCl}+\mathrm{Br}^{-} \longrightarrow \mathrm{Br}_{2} \mathrm{Cl}$ & $1.00 \times 10^{-11}$ & 2 & Michalowski et al. (2000) \\
$\mathrm{Br}_{2} \mathrm{Cl} \longrightarrow \mathrm{Br}^{-}+\mathrm{BrCl}$ & $3.34 \times 10^{5}$ & 1 & Wang et al. (1994) \\
$\mathrm{Br}_{2} \mathrm{Cl} \longrightarrow \mathrm{Br}_{2}+\mathrm{Cl}^{-}$ & $4.63 \times 10^{9}$ & 1 & Wang et al. (1994) \\
$\mathrm{Br}_{2}+\mathrm{Cl}^{-} \longrightarrow \mathrm{Br}_{2} \mathrm{Cl}$ & $1.00 \times 10^{-11}$ & 2 & Michalowski et al. (2000) \\
\hline
\end{tabular}

Table 2. Initial species concentrations in the snowpack. Here the concentration has the unit of [mol/(1 liter melted snow]. Thus, in the model where the unit [mol/(1 liter liquid-like layer] is used, the initial concentration should be divided by the total volume fraction of the liquid-like layer, $0.2 \%$.

\begin{tabular}{lcc}
\hline Species & $\begin{array}{c}\text { Concentration } \\
{[\mathrm{mol} / \mathrm{L}]}\end{array}$ & Reference \\
\hline $\mathrm{Br}^{-}$ & $2.0 \times 10^{-7}$ & Toom-Sauntry and Barrie (2002) \\
$\mathrm{Cl}^{-}$ & $9.0 \times 10^{-6}$ & Toom-Sauntry and Barrie (2002) \\
$\mathrm{H}^{+}$ & $1.0 \times 10^{-4}$ & Toyota et al. (2014) \\
$\mathrm{HOBr}$ & 0.0 & - \\
$\mathrm{Br}_{2}$ & 0.0 & - \\
$\mathrm{BrCl}$ & 0.0 & - \\
$\mathrm{Br}_{2} \mathrm{Cl}$ & 0.0 & - \\
\hline
\end{tabular}


Atmos. Chem. Phys. Discuss., doi:10.5194/acp-2016-553, 2016

Manuscript under review for journal Atmos. Chem. Phys.

Published: 7 July 2016

(c) Author(s) 2016. CC-BY 3.0 License.

(c) (1)

Table 3. Photolysis frequencies in the boundary layer, calculated by Lehrer et al. (2004) using the radiation transfer model (Röth, 1992, 2002) with the assumption of $\mathrm{SZA}=80^{\circ}$ and a surface albedo with the value of unity.

\begin{tabular}{lc}
\hline Species & $\mathrm{J}\left[\mathrm{s}^{-1}\right]$ \\
\hline $\mathrm{O}_{3}$ & $4.7 \times 10^{-7}$ \\
$\mathrm{Br}_{2}$ & $2.1 \times 10^{-2}$ \\
$\mathrm{BrO}$ & $1.4 \times 10^{-2}$ \\
$\mathrm{HOBr}$ & $3.0 \times 10^{-4}$ \\
$\mathrm{H}_{2} \mathrm{O}_{2}$ & $2.0 \times 10^{-6}$ \\
$\mathrm{HCHO} \rightarrow 2 \mathrm{HO}_{2}+\mathrm{CO}$ & $5.5 \times 10^{-6}$ \\
$\mathrm{HCHO} \rightarrow \mathrm{H}_{2}+\mathrm{CO}$ & $9.6 \times 10^{-6}$ \\
$\mathrm{C}_{2} \mathrm{H}_{4} \mathrm{O}$ & $6.9 \times 10^{-7}$ \\
$\mathrm{CH}_{3} \mathrm{O}_{2} \mathrm{H}$ & $1.2 \times 10^{-6}$ \\
$\mathrm{C}_{2} \mathrm{H}_{5} \mathrm{O}_{2} \mathrm{H}$ & $1.2 \times 10^{-6}$ \\
$\mathrm{HNO}_{3}$ & $4.4 \times 10^{-8}$ \\
$\mathrm{NO}_{2}$ & $3.5 \times 10^{-3}$ \\
$\mathrm{NO}_{3} \rightarrow \mathrm{NO}_{2}$ & $1.4 \times 10^{-1}$ \\
$\mathrm{NO}_{3} \rightarrow \mathrm{NO}_{\mathrm{BrONO}_{2}}$ & $1.7 \times 10^{-2}$ \\
$\mathrm{BrNO}_{2}$ & $3.4 \times 10^{-4}$ \\
$\mathrm{PAN}$ & $9.3 \times 10^{-5}$ \\
\hline
\end{tabular}


Atmos. Chem. Phys. Discuss., doi:10.5194/acp-2016-553, 2016

Manuscript under review for journal Atmos. Chem. Phys.

Published: 7 July 2016

(c) Author(s) 2016. CC-BY 3.0 License.

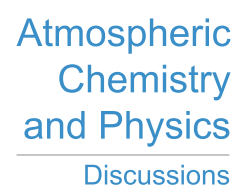

(c) (1)

Table 4. Initial air composition in the boundary layer and the snow interstitial air $(\mathrm{ppm}=$ parts per million, $\mathrm{ppb}=\mathrm{parts}$ per billion, $\mathrm{ppt}=\mathrm{parts}$ per trillion).

\begin{tabular}{lr}
\hline Species & Mixing ratio \\
\hline $\mathrm{O}_{3}$ & $40 \mathrm{ppb}$ \\
$\mathrm{Br}_{2}$ & $0.3 \mathrm{ppt}$ \\
$\mathrm{HBr}$ & $0.01 \mathrm{ppt}$ \\
$\mathrm{CH}_{4}$ & $1.9 \mathrm{ppm}$ \\
$\mathrm{CO}_{2}$ & $371 \mathrm{ppm}$ \\
$\mathrm{CO}$ & $132 \mathrm{ppb}$ \\
$\mathrm{HCHO}$ & $100 \mathrm{ppt}$ \\
$\mathrm{CH}_{3} \mathrm{CHO}$ & $100 \mathrm{ppt}$ \\
$\mathrm{C}_{2} \mathrm{H}_{6}$ & $2.5 \mathrm{ppb}$ \\
$\mathrm{C}_{2} \mathrm{H}_{4}$ & $100 \mathrm{ppt}$ \\
$\mathrm{C}_{2} \mathrm{H}_{2}$ & $600 \mathrm{ppt}$ \\
$\mathrm{C}_{3} \mathrm{H}_{8}$ & $1.2 \mathrm{ppb}$ \\
$\mathrm{NO}$ & $5 \mathrm{ppt}$ \\
$\mathrm{NO}_{2}$ & $10 \mathrm{ppt}$ \\
$\mathrm{H}_{2} \mathrm{O}$ & $800 \mathrm{ppm}$ \\
\hline
\end{tabular}

Table 5. Emission fluxes from the snowpack (Cao et al., 2014).

\begin{tabular}{lcc}
\hline Species & $\begin{array}{c}\text { Emission rates } \\
{\left[\text { molec. cm }{ }^{-2} \mathrm{~s}^{-1}\right]}\end{array}$ & Reference \\
\hline $\mathrm{NO}$ & $1.6 \times 10^{7}$ & Jones et al. $(2000,2001)$ \\
$\mathrm{NO}_{2}$ & $1.6 \times 10^{7}$ & Jones et al. $(2000,2001)$ \\
$\mathrm{HONO}$ & $1.6 \times 10^{7}$ & Grannas et al. (2007) \\
$\mathrm{H}_{2} \mathrm{O}_{2}$ & $1.0 \times 10^{8}$ & Jacobi et al. (2002) \\
$\mathrm{HCHO}$ & $6.0 \times 10^{7}$ & Jacobi et al. (2002) \\
\hline
\end{tabular}


Atmos. Chem. Phys. Discuss., doi:10.5194/acp-2016-553, 2016

Manuscript under review for journal Atmos. Chem. Phys.

Published: 7 July 2016

(c) Author(s) 2016. CC-BY 3.0 License.

(c) (i)
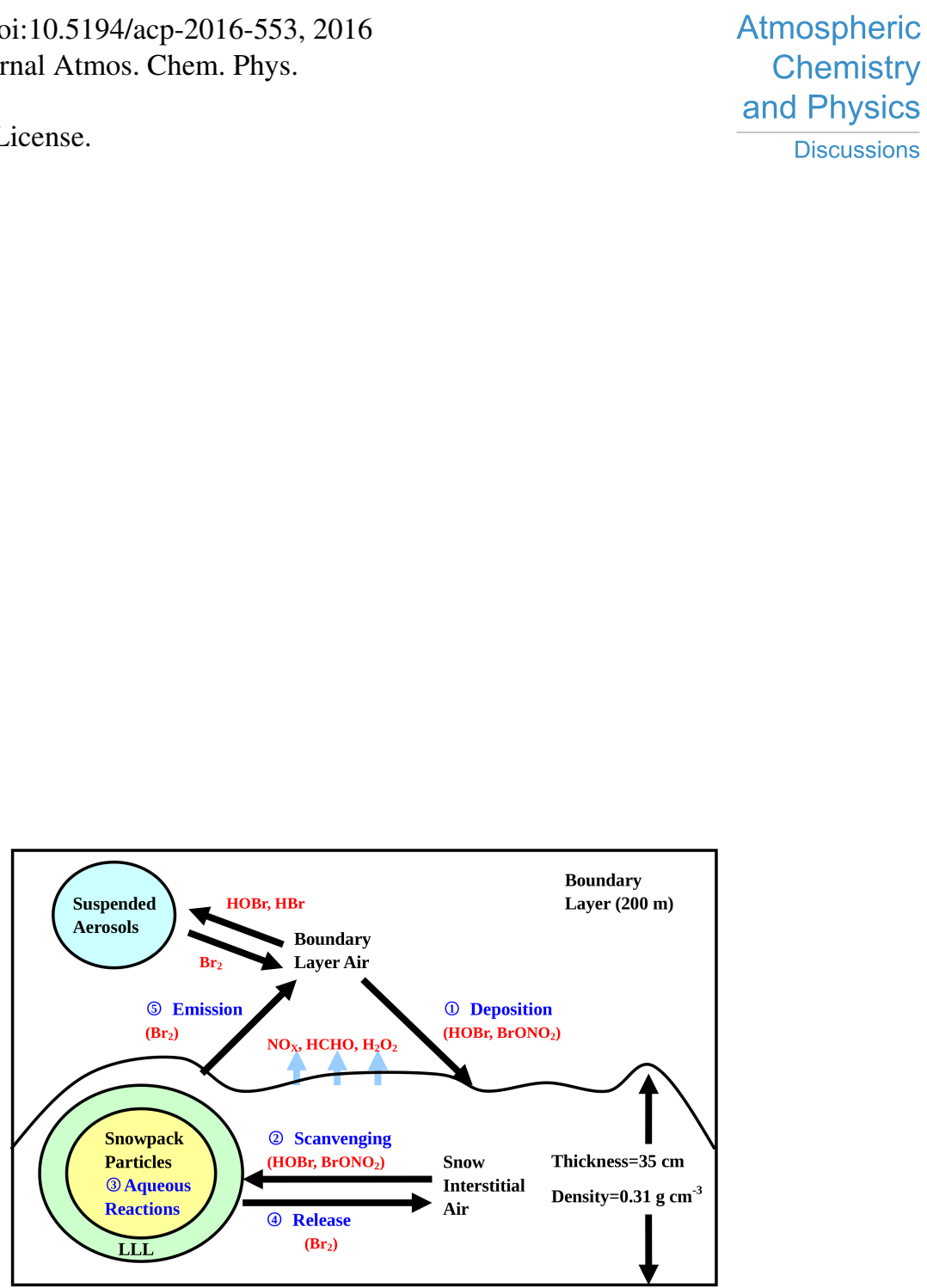

Figure 1. A schematic depiction of the model KINAL-SNOW. The suspended aerosols are able to absorb $\mathrm{HOBr}$ and $\mathrm{HBr}$, leading to the formation of $\mathrm{Br}_{2}$ which is then released to the boundary layer. Between the boundary layer air and the snowpack, mass exchange processes including the deposition of $\mathrm{HOBr}$ and the emission of $\mathrm{Br}_{2}$ take place. The details of the exchange processes are described in Sect. 2.1 of the manuscript. 
Atmos. Chem. Phys. Discuss., doi:10.5194/acp-2016-553, 2016 Manuscript under review for journal Atmos. Chem. Phys.

Published: 7 July 2016

(C) Author(s) 2016. CC-BY 3.0 License.
Atmospheric

Chemistry and Physics

Discussions

\section{(c) (7)}

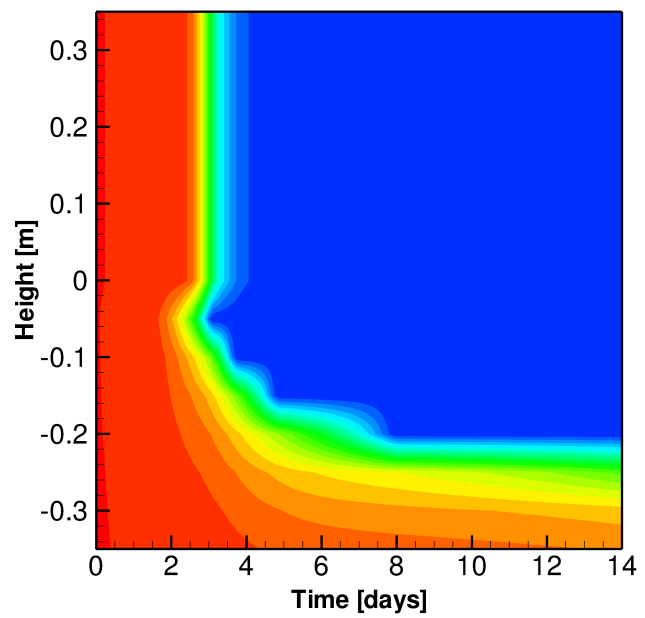

(a)

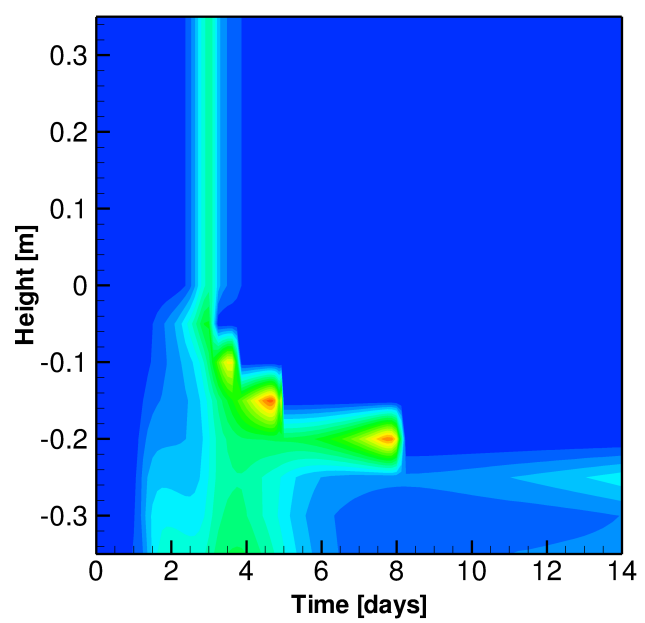

(c)
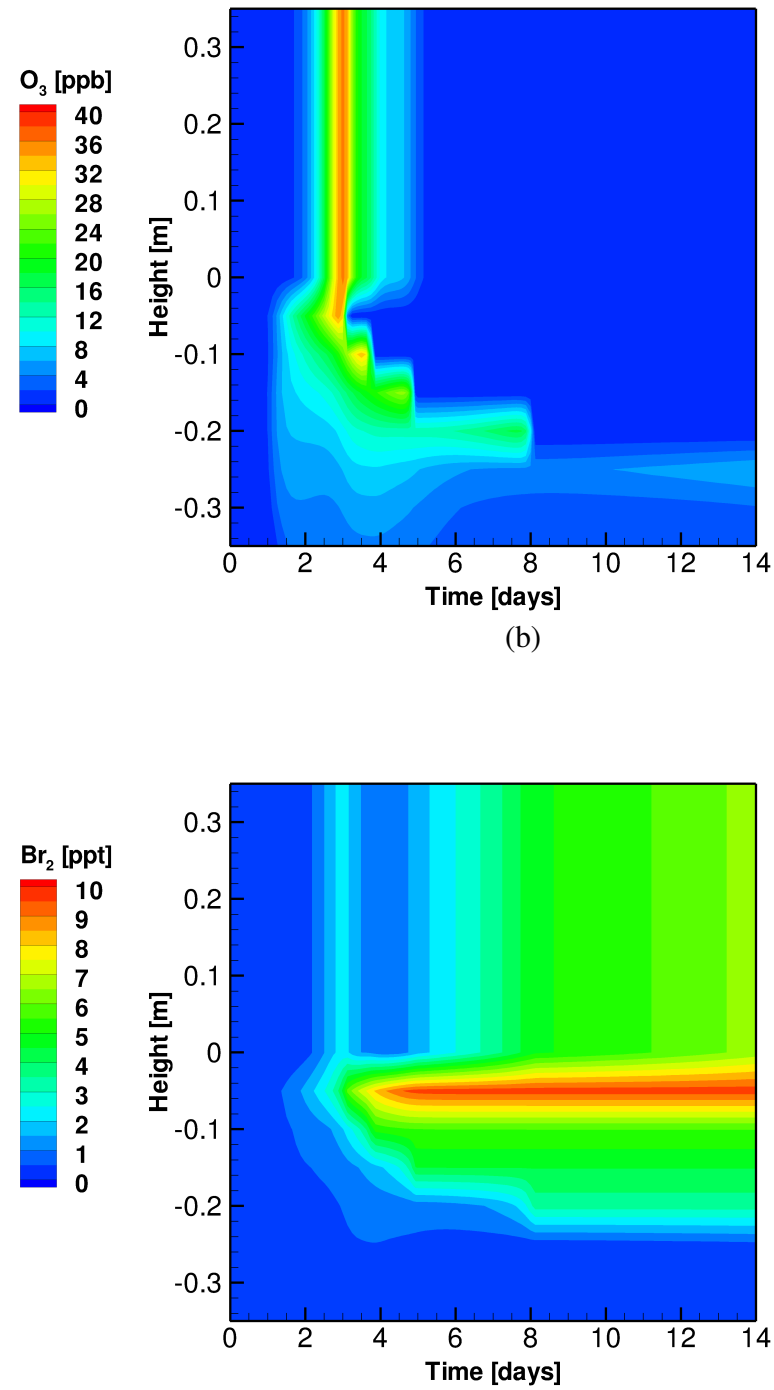

(d)

(b)
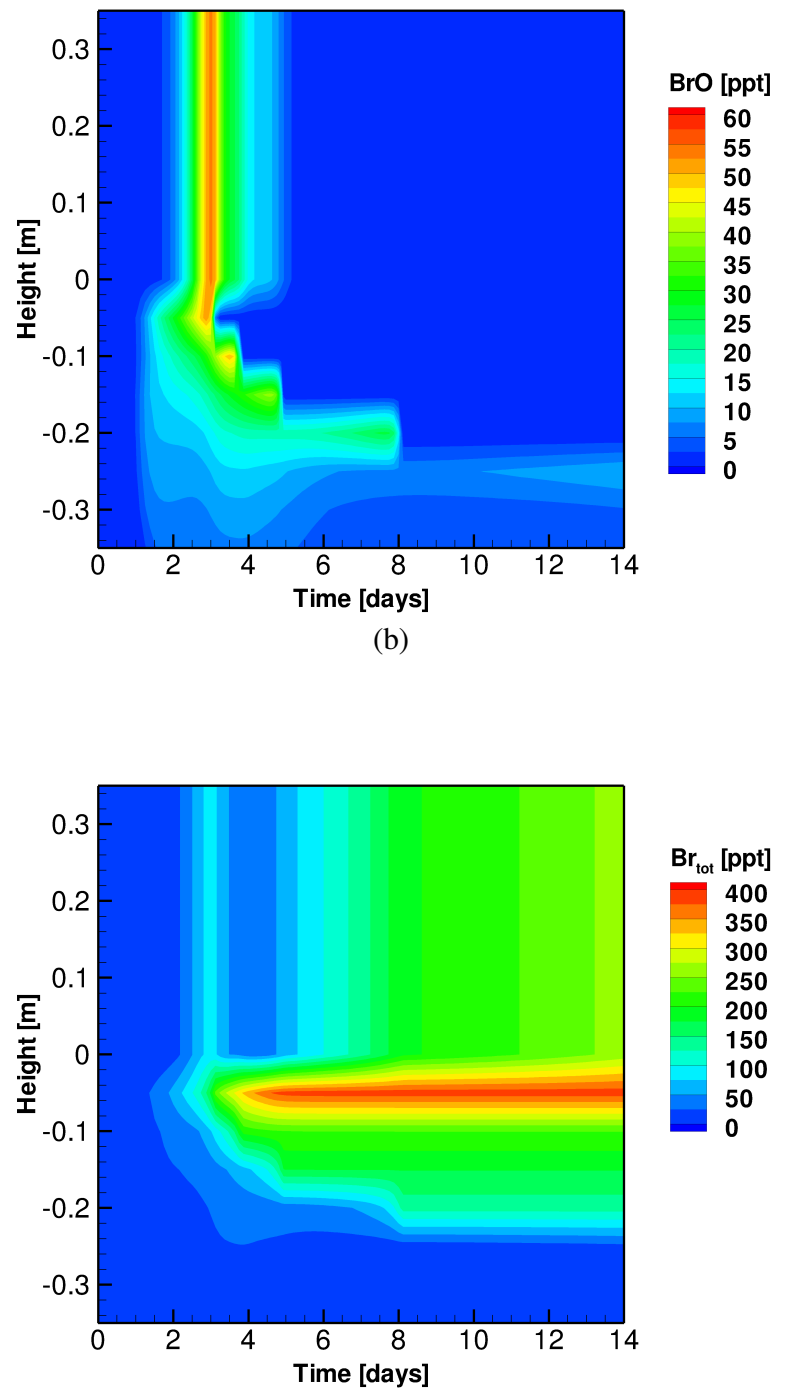

Figure 2. The temporal and spatial distributions of ozone and bromine species in the ambient air and the snow interstitial air for the standard scenario. The surface is located at Height $=0 \mathrm{~m}$. 
Atmos. Chem. Phys. Discuss., doi:10.5194/acp-2016-553, 2016

Manuscript under review for journal Atmos. Chem. Phys.

Published: 7 July 2016

(c) Author(s) 2016. CC-BY 3.0 License.

(c) (i)
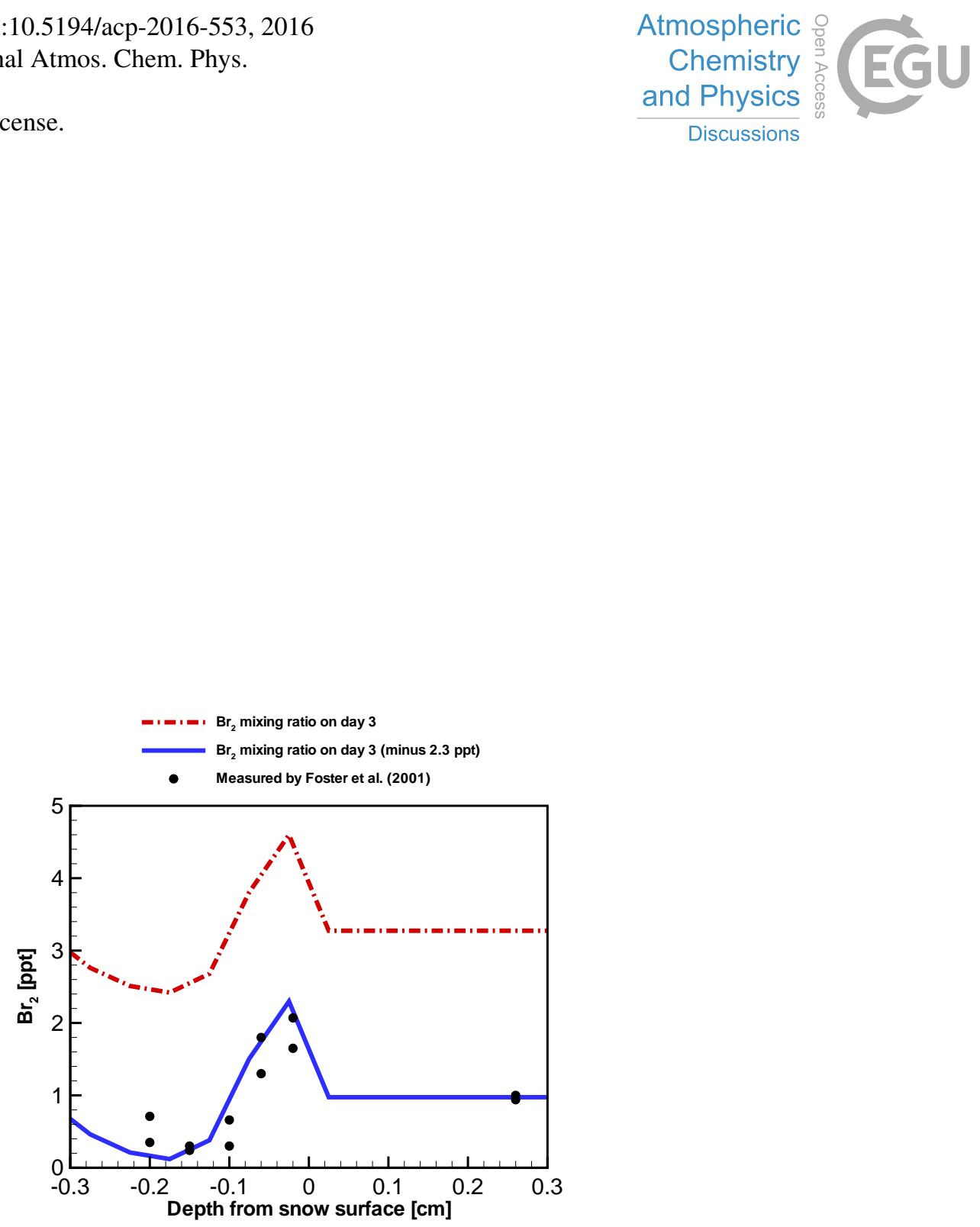

Figure 3. The vertical distribution of $\mathrm{Br}_{2}$ in the boundary layer and within the snowpack interstitial air (at the depth with negative values) obtained from the model results (dash dot line and curve line) and from observations (scattered points). In this figure, the dash dot line denotes the $\mathrm{Br}_{2}$ mixing ratio in the ambient air on day 3 which resides within the time period of the ozone depletion, and the curve line represents the modeled $\mathrm{Br}_{2}$ mixing ratios minus $2.3 \mathrm{ppt}$. 
Atmos. Chem. Phys. Discuss., doi:10.5194/acp-2016-553, 2016

Manuscript under review for journal Atmos. Chem. Phys.

Published: 7 July 2016

(C) Author(s) 2016. CC-BY 3.0 License.

\section{(c) (i)}

\section{Atmospheric \\ Chemistry \\ and Physics \\ Discussions}

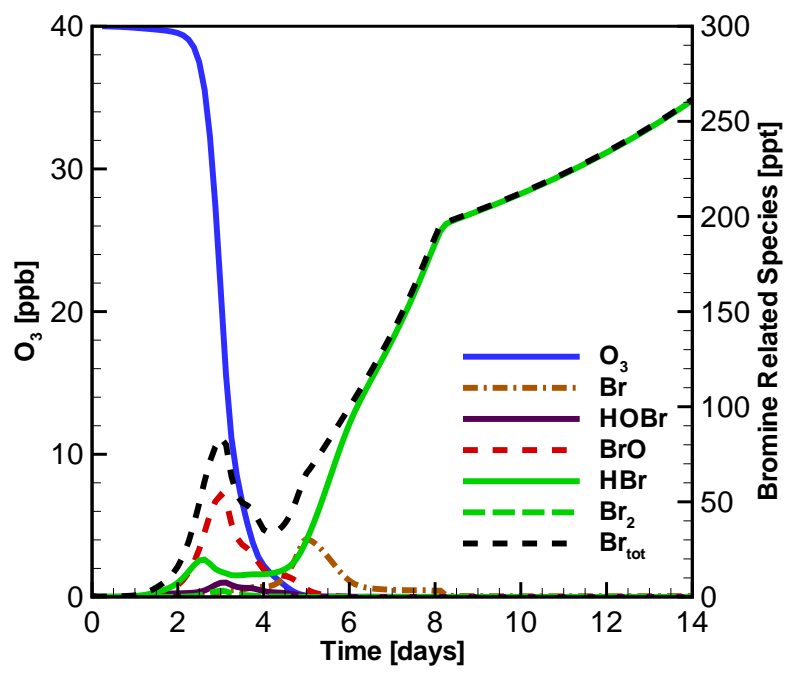

(a)

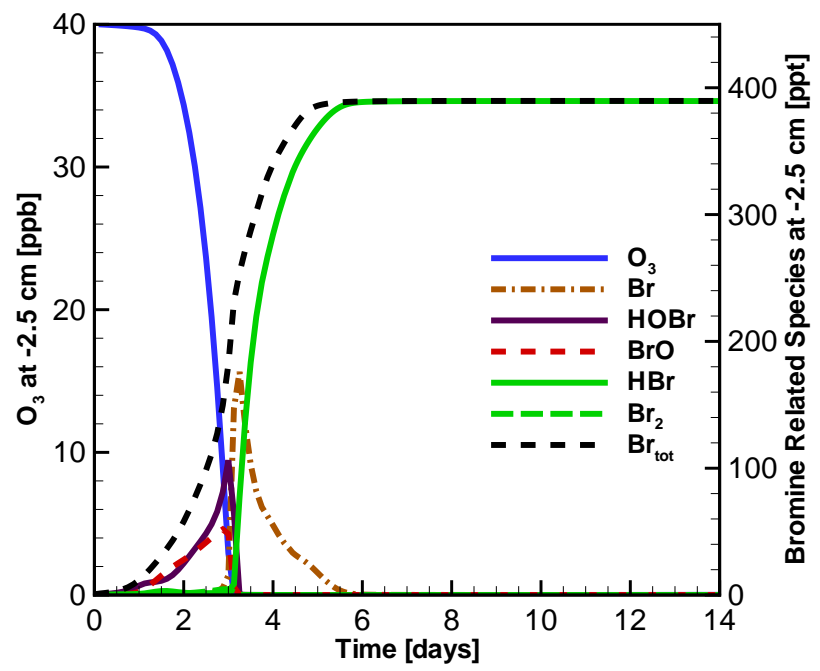

(b)

Figure 4. Temporal evolution of the mixing ratios of ozone and bromine species (a) in the ambient air of the $200 \mathrm{~m}$ boundary layer and (b) in the snow layer with the depth of $2.5 \mathrm{~cm}$ for the standard scenario. 
Atmos. Chem. Phys. Discuss., doi:10.5194/acp-2016-553, 2016

Manuscript under review for journal Atmos. Chem. Phys.

Published: 7 July 2016

(c) Author(s) 2016. CC-BY 3.0 License.

(c) (i)

\section{Atmospheric \\ Chemistry \\ and Physics \\ Discussions}

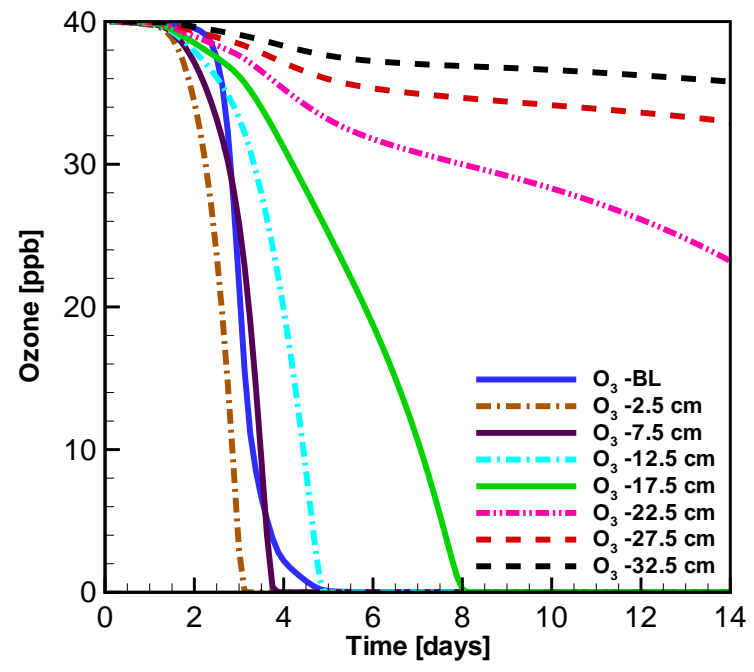

Figure 5. The temporal behavior of ozone in the boundary layer and within the interstitial air of each snow layer for the standard scenario. 
Atmos. Chem. Phys. Discuss., doi:10.5194/acp-2016-553, 2016

Manuscript under review for journal Atmos. Chem. Phys.

Published: 7 July 2016

(C) Author(s) 2016. CC-BY 3.0 License.

\section{(c) (i)}

\section{Atmospheric \\ Chemistry \\ and Physics \\ Discussions}

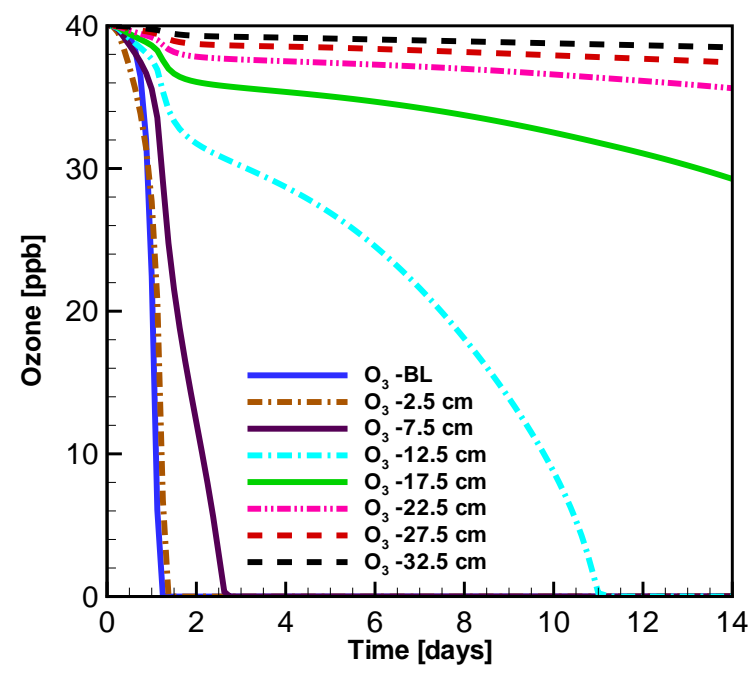

(a)

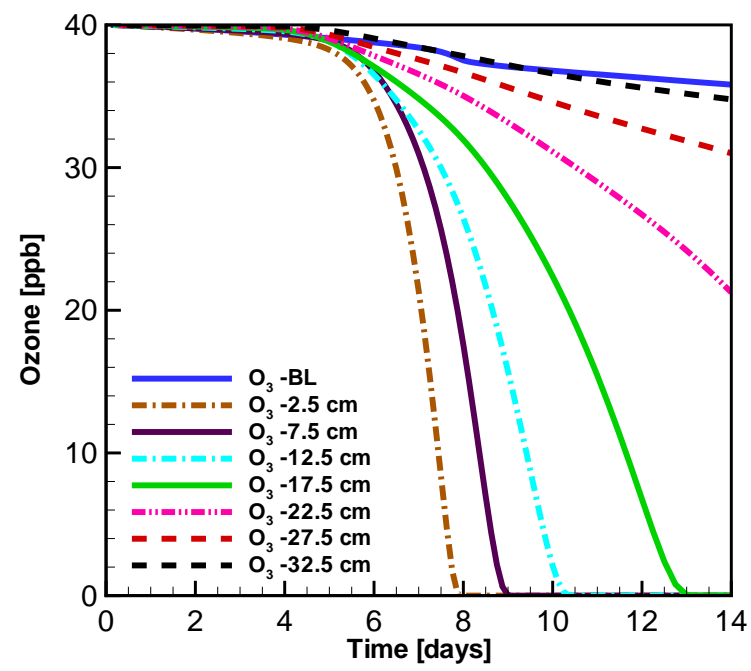

(b)

Figure 6. The temporal behavior of ozone in the boundary layer and the snow interstitial air when the diameter of the snow grains is changed from $1 \mathrm{~mm}$ (standard scenario) to (a) $0.3 \mathrm{~mm}$, (b) $2 \mathrm{~mm}$. 
Atmos. Chem. Phys. Discuss., doi:10.5194/acp-2016-553, 2016

Manuscript under review for journal Atmos. Chem. Phys.

Published: 7 July 2016

(c) Author(s) 2016. CC-BY 3.0 License.

\section{(c) (1)}

Atmospheric

Chemistry

and Physics

Discussions

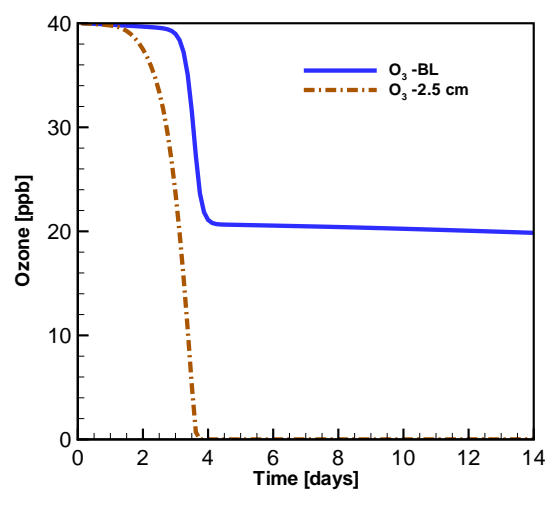

(a)

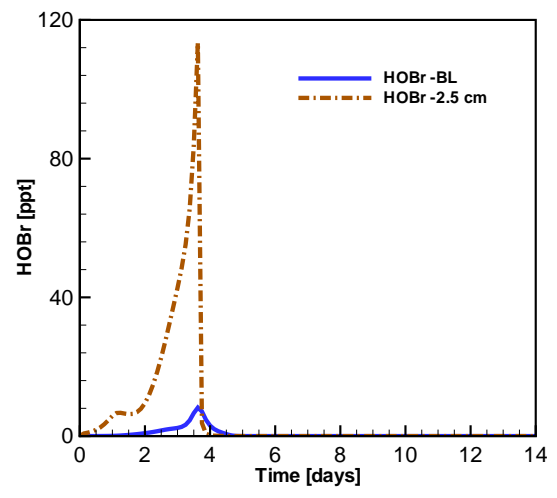

(c)

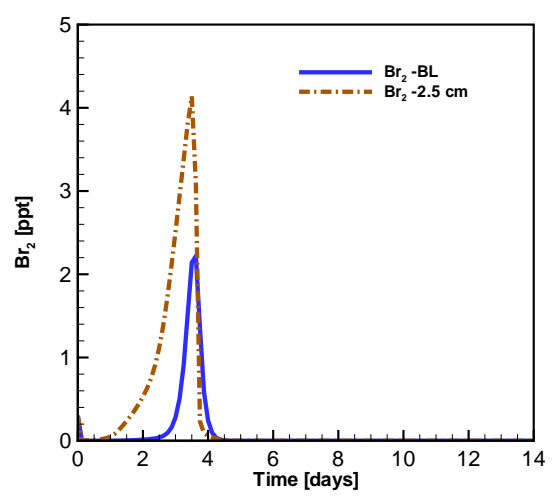

(e)

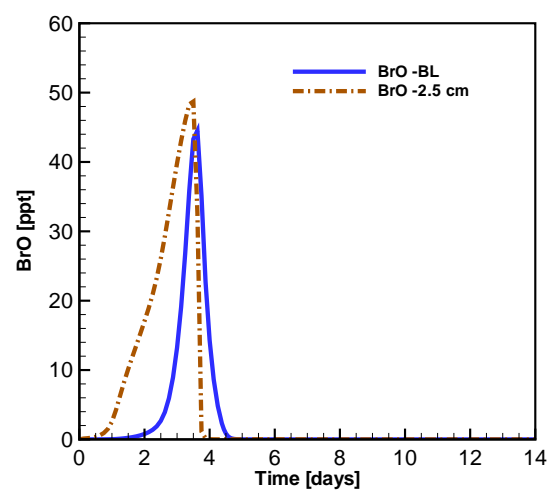

(b)

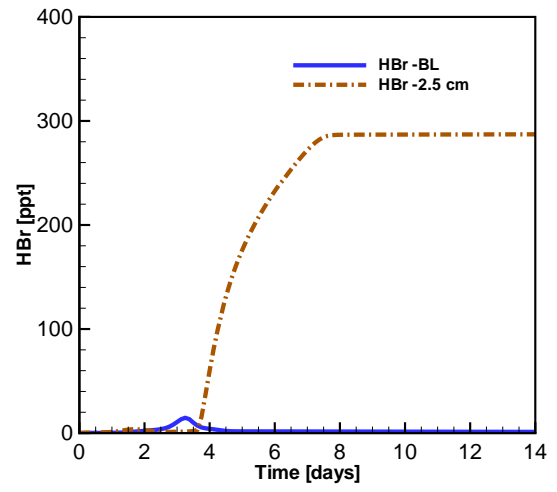

(d)

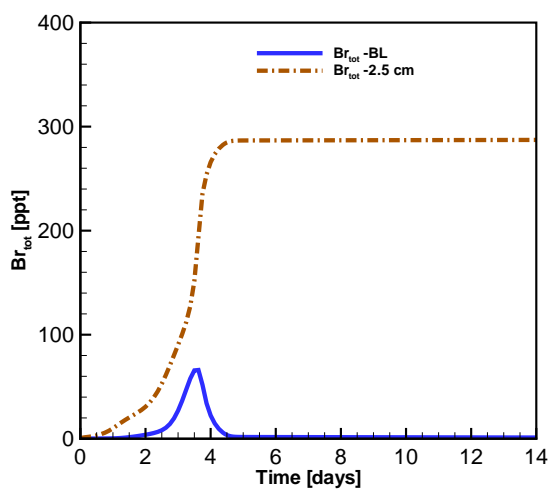

(f)

Figure 7. Temporal evolutions of ozone and principal bromine containing compounds in the boundary layer and the snow interstitial air, when the thickness of the snowpack is reduced to $5 \mathrm{~cm}$. It is found that the chemical processes are similar to the standard scenario $(35 \mathrm{~cm}$ snowpack thickness). However, the ozone depletion in the boundary layer is incomplete. 
Atmos. Chem. Phys. Discuss., doi:10.5194/acp-2016-553, 2016

Manuscript under review for journal Atmos. Chem. Phys.

Published: 7 July 2016

(C) Author(s) 2016. CC-BY 3.0 License.
Atmospheric

Chemistry

and Physics

Discussions (c) (1)

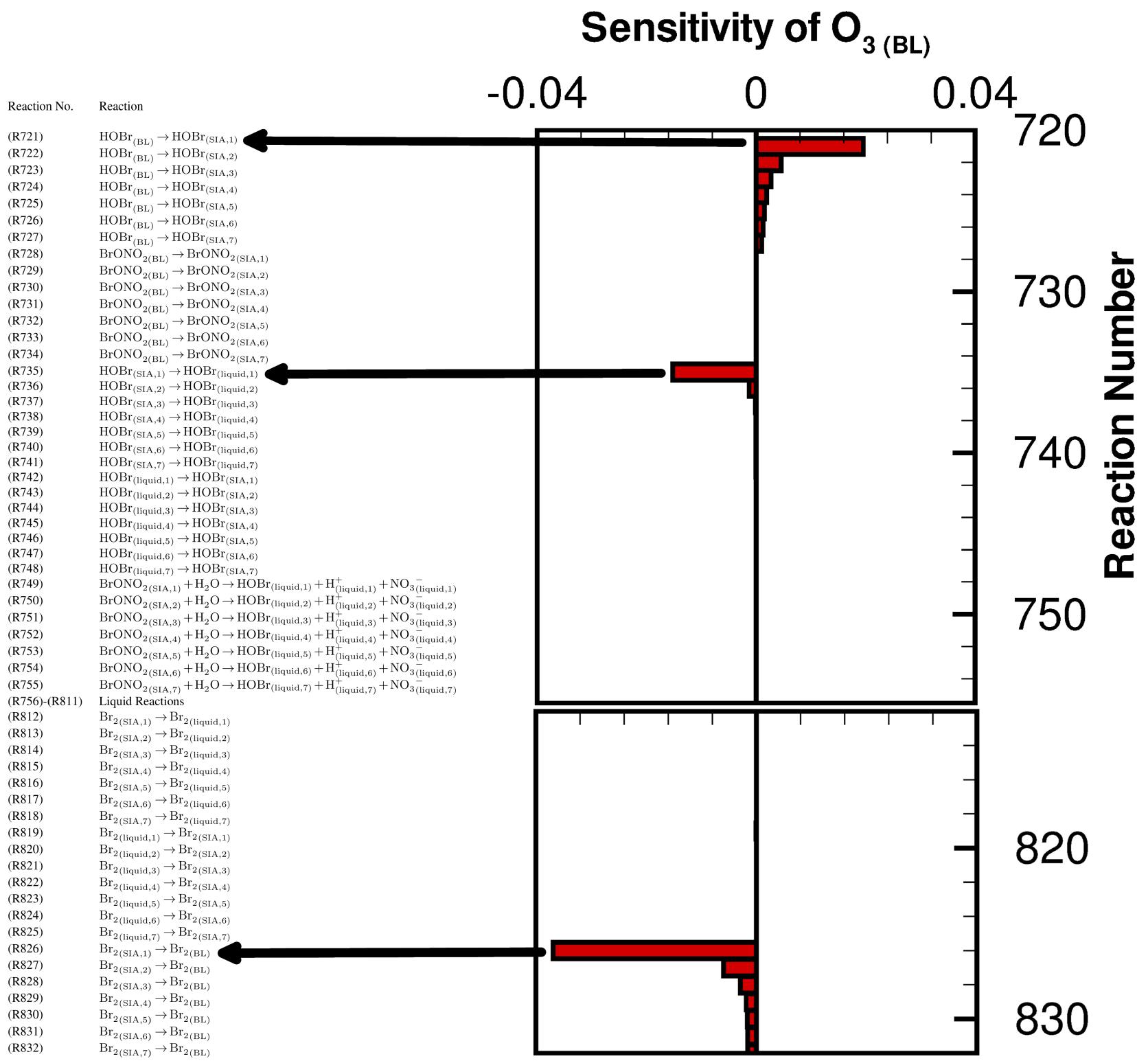

Figure 8. The relative concentration sensitivity of ozone in the boundary layer for the processes representing the mass transfer between the ambient air and the snowpack, on the time of day 3. 
Atmos. Chem. Phys. Discuss., doi:10.5194/acp-2016-553, 2016

Manuscript under review for journal Atmos. Chem. Phys.

Published: 7 July 2016

(C) Author(s) 2016. CC-BY 3.0 License.
Atmospheric

Chemistry

and Physics

Discussions (C) (1)

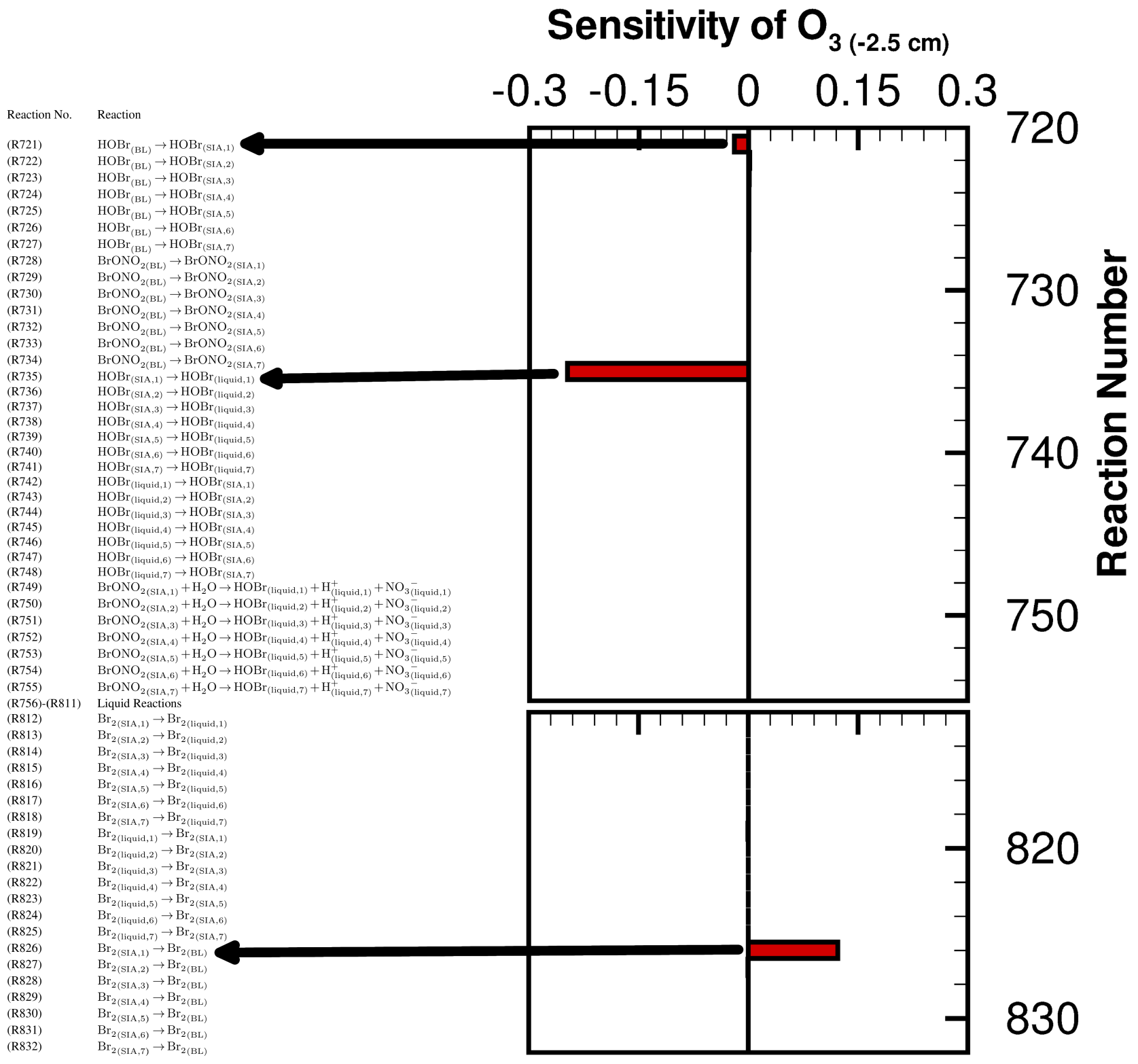

(a)

Figure 9. The relative concentration sensitivity of ozone in the interstitial air of the snow layers at the depth of (a) $2.5 \mathrm{~cm}$ and (b) $32.5 \mathrm{~cm}$ for each reaction step in the sequence of the mass transfer processes, on the time of day 3. (Continued...) 
Atmos. Chem. Phys. Discuss., doi:10.5194/acp-2016-553, 2016

Manuscript under review for journal Atmos. Chem. Phys.

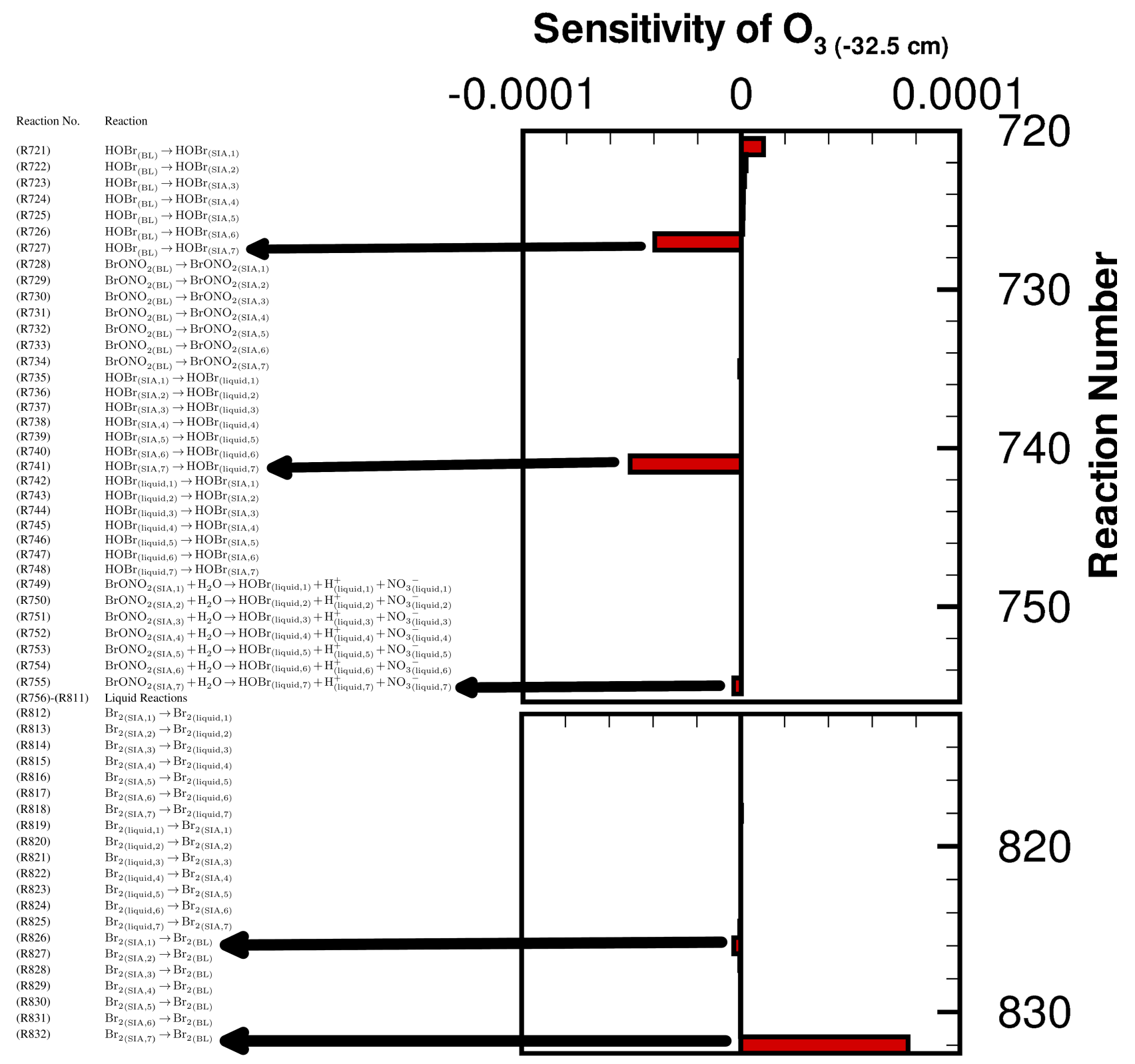

(b)

Figure 9. The relative concentration sensitivity of ozone in the interstitial air of the snow layers at the depth of (a) $2.5 \mathrm{~cm}$ and (b) $32.5 \mathrm{~cm}$ for each reaction step in the sequence of the mass transfer processes, on the time of day 3. 
Atmos. Chem. Phys. Discuss., doi:10.5194/acp-2016-553, 2016

Manuscript under review for journal Atmos. Chem. Phys.

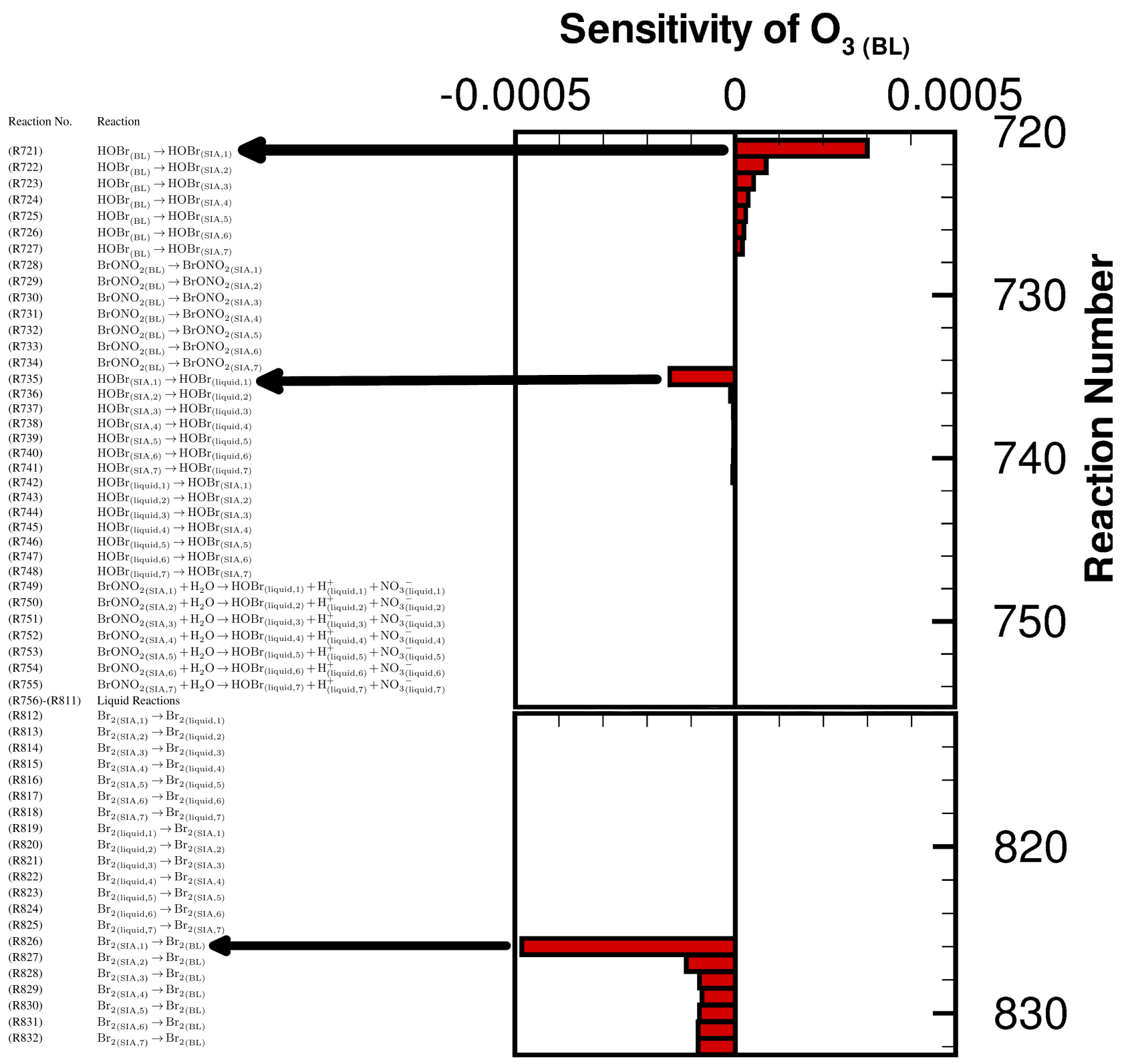

(a)

Figure 10. The relative concentration sensitivity of ozone in the boundary layer for the mass transfer processes between the ambient air and the snowpack on the time of (a) day 2 and (b) day 10. (Continued...) 
Atmos. Chem. Phys. Discuss., doi:10.5194/acp-2016-553, 2016

Manuscript under review for journal Atmos. Chem. Phys.

Published: 7 July 2016

(C) Author(s) 2016. CC-BY 3.0 License.
Atmospheric

Chemistry

and Physics

Discussions

(c) (i)

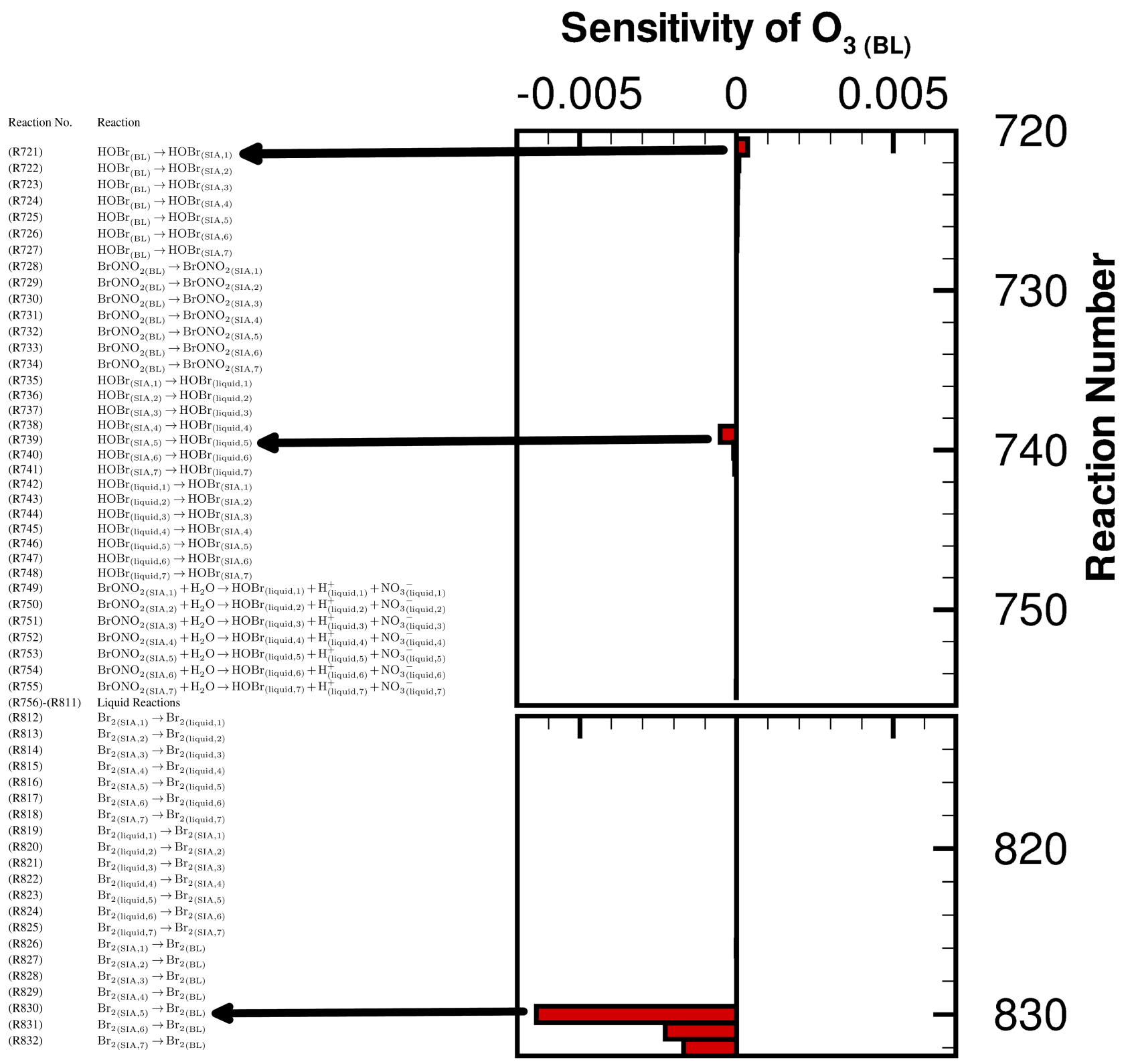

(b)

Figure 10. The relative concentration sensitivity of ozone in the boundary layer for the mass transfer processes between the ambient air and the snowpack on the time of (a) day 2 and (b) day 10. 